\title{
Pukara de los wak'a. Cerros, muros concéntricos y divinidades tutelares en el altiplano centro-sur andino
}

Pukara des wak'a. Collines, murs concentriques et divinités tutélaires au sud de l'altiplano central andin

Pukara of the wak'a. Hills, concentric walls and tutelary divinities in the southcentral Andean altiplano

Pablo Cruz y Richard Joffre

\section{OpenEdition}

Journals

Edición electrónica

URL: http://journals.openedition.org/jsa/18487

ISSN: 1957-7842

Editor

Société des américanistes

Edición impresa

Fecha de publicación: 15 diciembre 2020

Paginación: 47-76

ISSN: 0037-9174

\section{Referencia electrónica}

Pablo Cruz y Richard Joffre, «Pukara de los wak'a. Cerros, muros concéntricos y divinidades tutelares en el altiplano centro-sur andino», Journal de la Société des américanistes [En línea], 106-2 | 2020, Publicado el 30 diciembre 2020, consultado el 12 marzo 2021. URL: http://journals.openedition.org/ jsa/18487 


\title{
Pukara de los wak'a. Cerros, muros concéntricos y divinidades tutelares en el altiplano centro-sur andino
}

\author{
Pablo Cruz y Richard Joffre *
}

\begin{abstract}
$\mathrm{Al}$ corroborar las informaciones proporcionadas por las fuentes documentales coloniales, se identificaron en distintas regiones del altiplano centro-sur andino (Bolivia) una cuantiosa cantidad de espacios ceremoniales vinculados con los antiguos cultos a los wak'a tutelares. Ubicados sobre las cimas de cerros no muy elevados y cercanos a los poblados, estos se distinguen por presentar un número variable de muros en piedra dispuestos de manera concéntrica. Aunque la cronología de estos sitios se remonta a la época prehispánica, la mayoría de ellos se mantuvo vigente en el tiempo largo. Articulando nuevos datos arqueológicos con informaciones históricas y etnográficas, en este trabajo se presentan y se analizan diversos aspectos de estos sitios ceremoniales del altiplano andino. [Palabras clave: wak'a, cerro tutelar, pukara ceremonial, altiplano andino.]
\end{abstract}

Pukara des wak'a. Collines, murs concentriques et divinités tutélaires au sud de l'altiplano central andin. En corroborant les informations de sources documentaires coloniales, nous avons identifié dans la région centre-sud de l'Altiplano bolivien un grand nombre d'espaces cérémoniels associés aux anciens cultes aux wak'a tutélaires. Situés au sommet de collines peu élevées et proches des villages, ces sites se caractérisent par un nombre variable de murs en pierre concentriques. Bien que leur chronologie les rattache à l'époque préhispanique, la plupart de ces sites sont restés actifs dans le long terme. Articulant de nouvelles données archéologiques avec des informations historiques et ethnographiques, cet article présente et analyse divers aspects de ces espaces cérémoniels du haut plateau andin. [Mots-clés : wak'a, colline tutélaire, pukara cérémonielle, haut plateau andin.]

Pukara of the wak'a. Hills, concentric walls and tutelary divinities in the southcentral Andean altiplano. According to information provided by colonial documentary sources, a large number of ceremonial spaces linked to the ancient cults of the tutelary wak' $a$ were identified in different regions of the central-southern Andean

* P. CRUz: UE-CISOR CONICET-UNJu, Investigador asociado EREA-LESC (MSH Mondes, université Paris Nanterre), San Salvador de Jujuy, Argentina [saxrapablo@ gmail.com]; y R. JofFre: CEFE, CNRS, université de Montpellier, université Paul-Valéry Montpellier 3, EPHE, IRD, Montpellier, France [richard.joffre@cefe.cnrs.fr]. 
highlands (Bolivia). Placed on the tops of low hills and close to the settlements, they are distinguished by a variable number of stone walls arranged in a concentric manner. Although their chronology begins in pre-Hispanic times, the majority of these sites continued to be in use in the long term. Articulating new archaeological data with historical and ethnographic information, this paper presents and analyzes different aspects of these ceremonial spaces in the Andean highlands. [Key words: wak'a, tutelary hill, ceremonial pukara, highlands.]

Uno de los principales problemas que enfrentó la Iglesia en su afán por evangelizar y convertir las almas de los indígenas andinos fue la profusión y diversidad de wak'a, que se encontraban presentes prácticamente en todos los ámbitos de la vida social. Esa omnipresencia hizo de la prioritaria erradicación de los cultos indígenas una empresa interminable, cuando no imposible, de llevar a cabo. De hecho, la intensa actividad que continuaban teniendo los curas extirpadores durante las primeras décadas del siglo XVII refleja la permanencia de estos cultos cuando el régimen colonial se encontraba ya totalmente consolidado. Así, en su primera visita de 1611 al corregimiento de Huarochirí, Francisco de Ávila (1966 [1611], p. 255) cuenta haber destruido en solo cinco doctrinas más de 5000 ídolos indígenas. De la misma manera, el jesuita Pablo Joseph de Arriaga (1621, p. 9) nos dice que solo en un año y medio, entre febrero de 1617 y julio de 1618, se descubrieron y se destruyeron en el corregimiento de Chancay 603 wak'a principales.

Bajo el término polisémico de wak'a, una palabra en que se condensa toda una categoría de pensamiento, se identificaba en los Andes a los cerros sagrados, las deidades y sus representaciones, y los espacios religiosos donde estos se encontraban depositados. Esta amplitud conceptual se expresa en las conocidas traducciones de la palabra que hicieron Bertonio (1984 [1612]): "ídolo en forma de hombre, carnero, y los cerros que adoraban en su gentilidad" y Santo Tomás (1951 [1560]): "ydolo, templo de ydolos, o el mismo ydolo". En acuerdo con estas definiciones, las informaciones recopiladas por los clérigos españoles sobre los cultos a los wak'a reflejan una estructura religiosa estratificada en la que se articularon distintas categorías de objetos y entidades no-humanas, niveles de sacralidad (Estenssoro Fuchs 2003, p. 96) y escalas políticas y territoriales (Bouysse-Cassagne y Chacama 2012). Así, en su relación sobre la región de Huarochirí, Ávila se refiere a la existencia en cada poblado de ídolos mayores y menores, siendo estos particulares a cada familia o generales a la comunidad, al ayllu o a la provincia. Y en lo más alto de esta estructura religiosa se encontraban las altas cumbres andinas, seguidas por una miríada de cerros no muy elevados y colinas cercanas a los poblados que eran considerados como entidades tutelares. A diferencia de los miles de ídolos en piedra que fueron destrozados a golpes de mazo, las momias de los ancestros quemadas, y los templos y adoratorios expoliados y demolidos, no había forma de atentar contra los colosales cuerpos de estos wak'a principales. Esta evidente imposibilidad permitió que la devoción 
a las montañas se mantuviera en el tiempo largo, sedimentándose en sus cumbres los cultos de aquellos otros wak'a que resultaron amputados.

Al articular la teledetección con los datos arqueológicos, las informaciones proporcionadas por las fuentes documentales y el registro etnográfico, este trabajo presenta y analiza un amplio conjunto de espacios ceremoniales ubicados en el altiplano boliviano que se vinculan con los antiguos cultos a los cerros-wak'a tutelares. El número elevado de sitios identificados indica que se trató de un fenómeno a la vez particular y generalizado en esta parte de los Andes. Los resultados alcanzados en este estudio amplían nuestra mirada acerca de las distintas escalas de los cultos andinos a las montañas y su permanencia a largo plazo.

\section{Los sitios con cercos concéntricos del Altiplano central}

Estudios realizados en torno a los antiguos sistemas agrícolas prehispánicos del altiplano surandino permitieron identificar un número elevado de sitios ceremoniales vinculados con las áreas de cultivo. Estos sitios se destacan visualmente por encontrarse ubicados en la cima de cerros no muy elevados y por presentar un número variable de amurallamientos o de cercos concéntricos en torno a un espacio central. Para facilitar la lectura, de aquí en adelante denominaremos SCC a los sitios con cercos concéntricos.

Partiendo del análisis de imágenes satelitales, se identificaron a la fecha 135 sitios con estas características en distintas zonas de la región de Carangas y en las vecinas regiones de Quillacas e Intersalar (Figura 1, página siguiente). Una primera etapa de la investigación consistió en el recorrido de estos sitios con el fin de corroborar y de completar las informaciones satelitales. Dada la cantidad de registros, los estudios de campo se centraron en 10 de estos sitios $^{1}$ (Figura 2, páginas siguientes), que fueron considerados, en una primera instancia, como representativos de la variabilidad de casos observados. Durante estas actividades resultaron esenciales las informaciones proporcionadas por los pobladores locales, que nos alumbraron con sus elocuciones acerca de la gravitación simbólica que mantienen estos sitios en la actualidad. En una segunda etapa de la investigación se procesaron los datos de campo, se sistematizaron las informaciones arqueológicas relativas a la región y al tema abordado, y se procedió a la exégesis de las fuentes documentales coloniales. La articulación de los datos arqueológicos con los registros histórico y etnográfico nos permitió una mejor comprensión de la funcionalidad y de los múltiples sentidos de estos espacios religiosos en el tiempo largo. Por último, es importante señalar que no se trata de un fenómeno particular a estas tres regiones del altiplano

1. Estos se encuentran en las localidades de Lakasa (OrLac05), San Martín (OrLac04), Orinoca (OrSuc11, OrSuc17), Rosapata (OrSuc12), Yuruna (OrSuc02, OrSuc03), Corque (OrCar07), Cruz de Huayllamarca (OrSuc19, OrSuc21). 


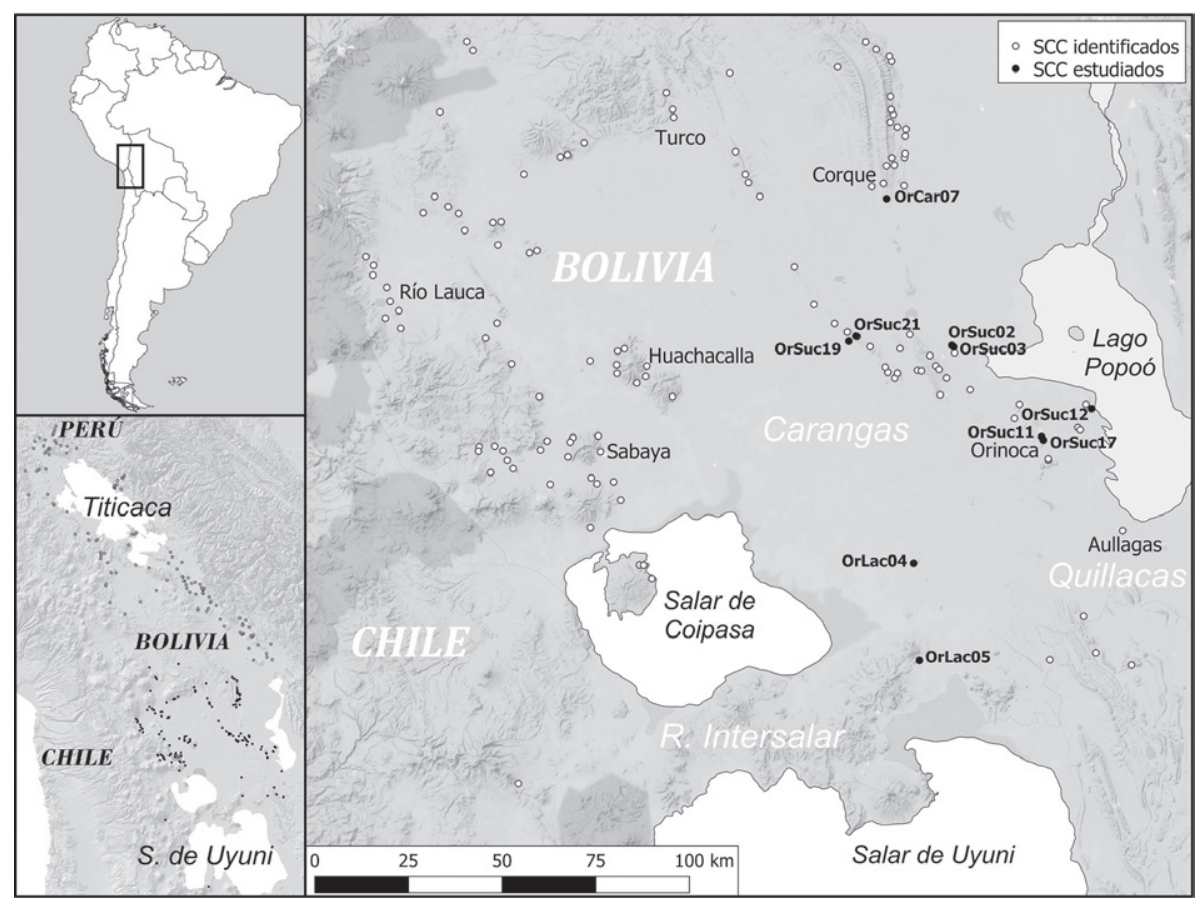

Fig. 1 - Localización de los SCC que se encuentran en las regiones de Carangas, Quillacas e Intersalar. En el mapa pequeño, abajo a la izquierda, se incluyen los sitios ubicados al norte del área de estudio y que fueron identificados en imágenes satelitales de alta resolución (elaboración de los autores; fuentes:

Geoeyes, Digital Globe, CNES/Astrium, CNES/Airbus, Google Earth)

boliviano que se abordan en este estudio, pues a partir de imágenes satelitales se han identificado igualmente una cantidad comparable de sitios con amurallamientos concéntricos (120 casos) en la región de Pacajes y en todo el altiplano circumlacustre del Titicaca (Bolivia y Perú). Estos sitios serán objeto de futuros estudios, razón por la cual no se incluyen en este trabajo.

Todos los SCC identificados se ubican en las cimas de cerros y colinas cuya altura varía solo entre $100 \mathrm{~m}$ y $400 \mathrm{~m}$ con respecto a las planicies (3700-3900 m) (Figura 3, páginas siguientes). La gran mayoría de ellos (92\%) se encuentra directamente relacionado con antiguas superficies de producción agrícola. Del total de sitios registrados, 47 (35\%) se ubican a menos de $2 \mathrm{~km}$ de una comunidad o poblado habitado en la actualidad, 54 (40\%) entre $2 \mathrm{~km}$ y $5 \mathrm{~km}$, y 35 (26\%) a más de $5 \mathrm{~km}$. La superficie total de los sitios varía sustancialmente, ocupando $900 \mathrm{~m}^{2}$ el más reducido y 17 ha el más extenso. No obstante, la mayoría de ellos (74\%) ocupa una superficie menor a las 2 ha, contabilizándose solo 12 casos que superan las 4 ha. Por su parte, la superficie de los espacios 
Cerros, muros concéntricos y divinidades tutelares en el altiplano centro-sur andino

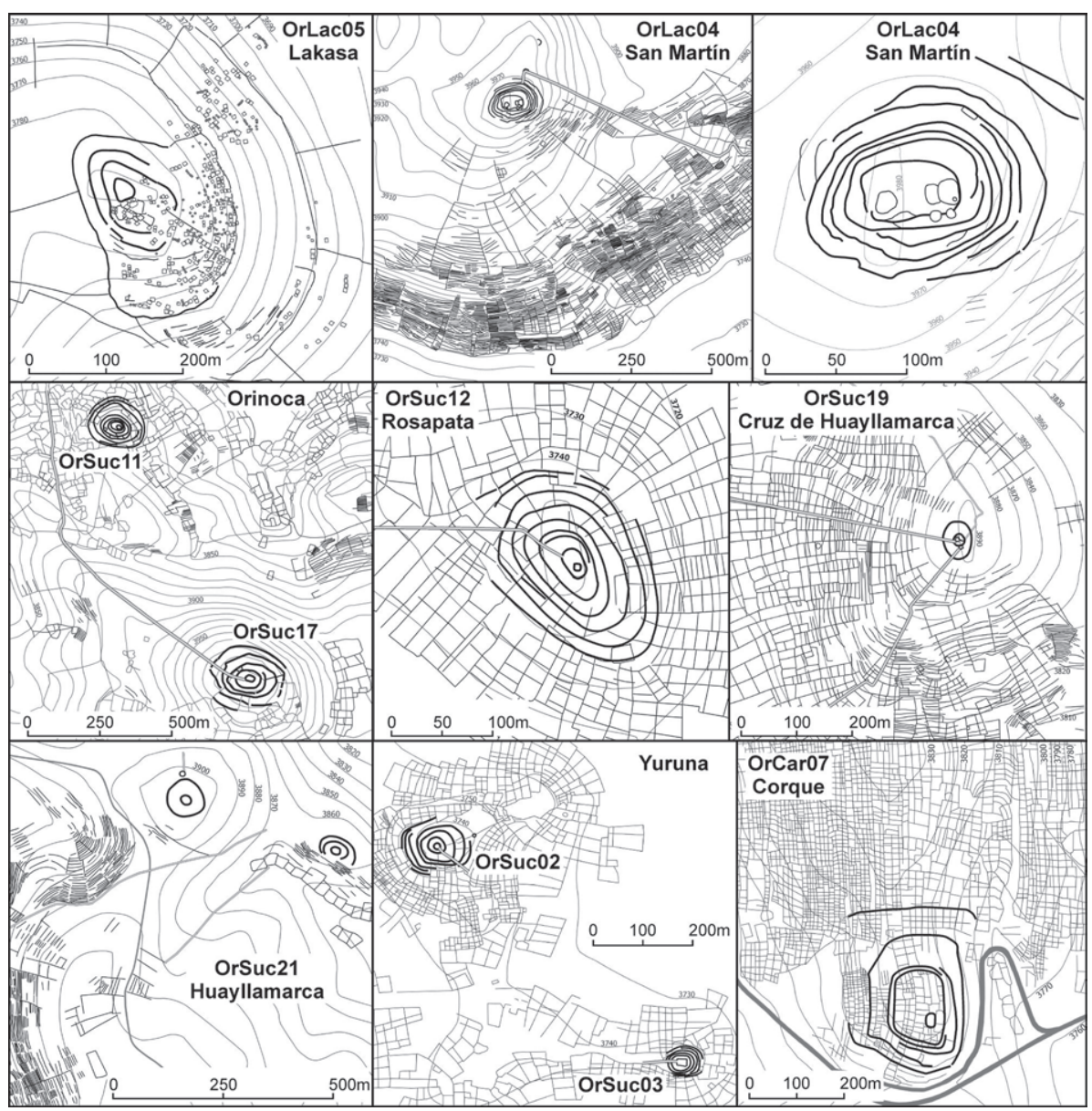

Fig. 2 - Planimetría de los 10 SCC estudiados en detalle.

El trazo grueso corresponde a los muros concéntricos (elaboración P. Cruz)

centrales de estos sitios, generalmente de forma circular u ovalada, es menos variable. En un $65 \%$ de los casos es menor a $500 \mathrm{~m}^{2}$, un $22 \%$ tiene entre $500 \mathrm{~m}^{2}$ y $1000 \mathrm{~m}^{2}$ y solamente un $13 \%$ supera los $1000 \mathrm{~m}^{2}$. De manera general, estas superficies se presentan como plazas centrales, con frecuencia teniendo en sus bordes perimetrales, o en proximidad de ellos, uno o varios recintos de piedra. La cantidad de murallas o de cercos concéntricos también difiere de un sitio a otro: 27 sitios cuentan con solo dos cercos, 45 tres cercos, 30 cuatro cercos, 31 poseen entre 5 y 7 cercos, y solo hay 2 sitios con 8 y 9 cercos. Por otro lado, solo un $25 \%$ de los sitios presenta cercos concéntricos de contorno circular regular, siendo en la mayoría de los casos irregulares en función del relieve que tienen las laderas. Sin embargo, en todos los casos los espacios 

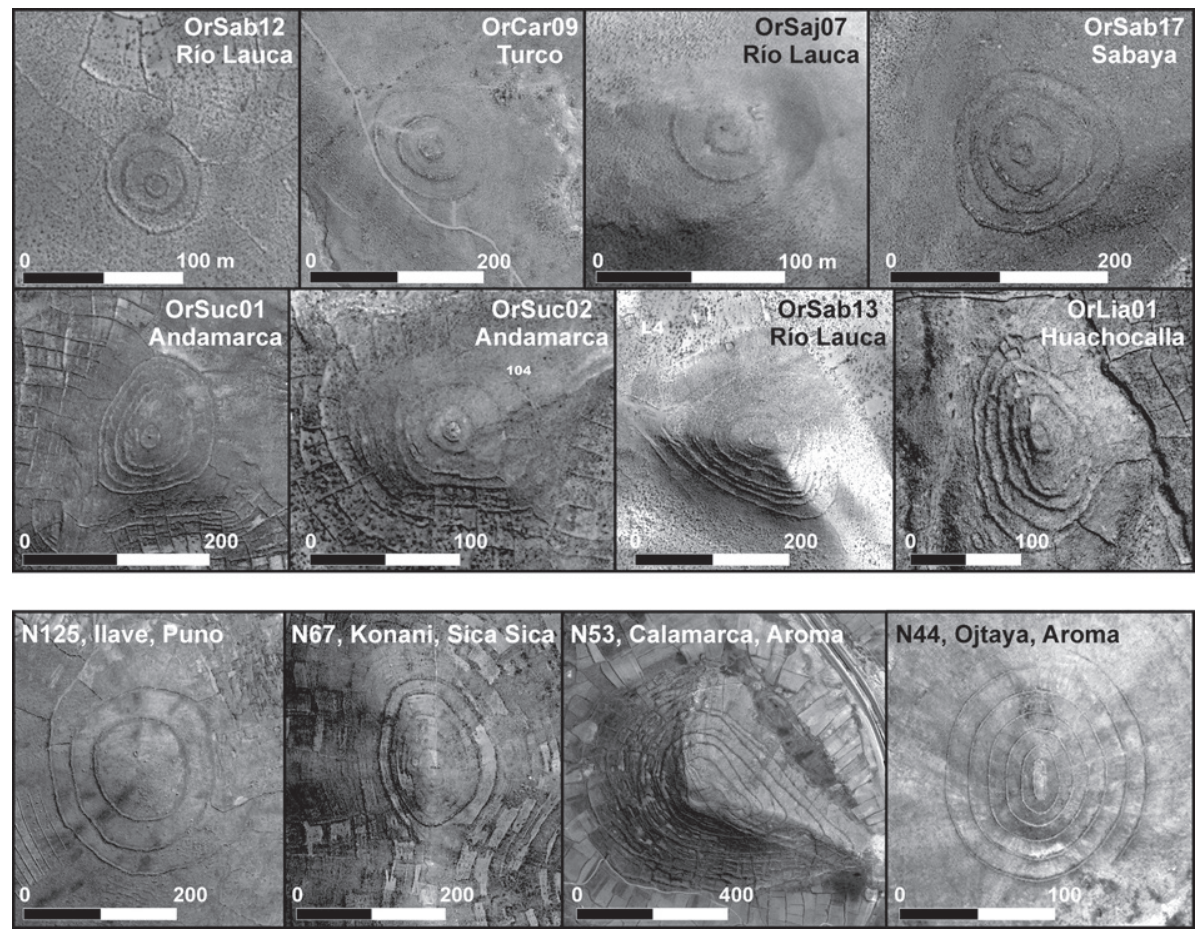

Fig. 3 - Imágenes satelitales de SCC en las que se observa el número variable de muros concéntricos. Los cuatro de abajo se localizan al norte del área de estudio, en distintas localidades del altiplano de Bolivia y Perú. Se incluyen a fin de subrayar que se trata de un fenómeno general a toda el área del Altiplano central

(elaboración de los autores; fuentes: Geoeyes, Digital Globe, CNES/Astrium, CNES/Airbus, Google Earth)

centrales se encuentran delimitados por un cercado circular u ovalado bien definido. En cuanto al tipo de cerco, predominan uno con muros de piedras construidos a modo de pirca, y otro con muros de contención que conforman y delimitan superficies aterrazadas. Estos últimos poseen generalmente accesos escalonados o en rampa que permiten la circulación de un nivel al otro. Entre los SCC registrados con este tipo de cercado se destacan los ubicados en las localidades de San Martín y Rosapata, en donde los distintos niveles de superficies aterrazadas modelaron significativamente el contorno de las colinas donde se ubican (Figura 4). La altura y el grosor de los muros varían de un sitio al otro, e incluso dentro de un mismo sitio, pudiendo tratarse de muros simples o a doble paramento. Tal es el caso de los sitios de Lakasa y San Martín, donde los muros concéntricos alcanzan 1,20 m de espesor y $2 \mathrm{~m}$ de altura. Solo en un caso, Cruz de Huayllamarca (OrSuc19), los muros que delimitan el espacio central presentan segmentos con nichos y zócalos. 


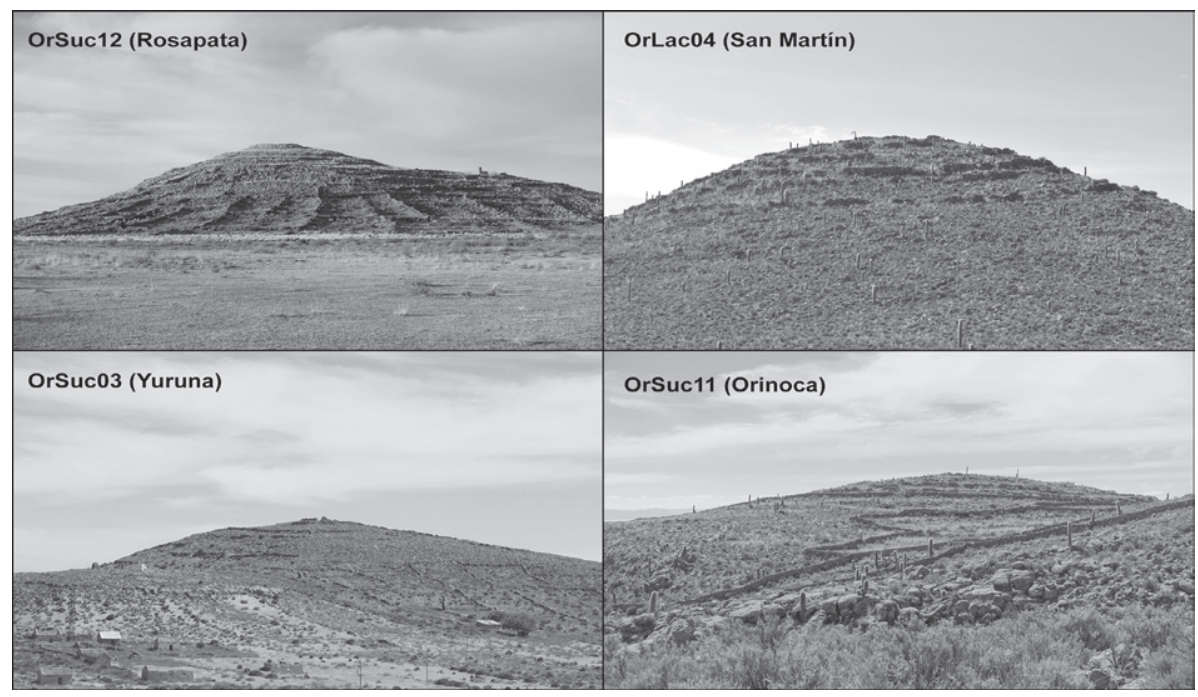

Fig. 4 - Fotografías de 4 SCC de la región de Carangas.

Nótese cómo los muros concéntricos y las superficies aterrazadas modelaron el perfil de las colinas donde estos sitios se ubican (fotos de los autores)

Por su parte, 66 sitios poseen en su espacio central un edículo, una torre o una capilla-posa, siendo muchas de ellas del Periodo Colonial (Figura 5, página siguiente), mientras que otros 17 sitios albergan construcciones más importantes y recientes. De igual manera, 43 sitios tienen un camino o sendero de acceso, en su gran mayoría de trayecto rectilíneo. En al menos 13 casos estos caminos tienen segmentos empedrados y escalinatas, destacándose también su ancho (entre $3 \mathrm{~m}$ y $5 \mathrm{~m}$ ). Asimismo, en las cercanías de $39 \mathrm{SCC}$, con frecuencia al lado de los caminos de acceso, se ubica un recinto de piedra de contorno circular. La ubicación de estos espacios circulares, visualmente conectados con los SCC, resulta compatible con la figura de "cayan", es decir, espacios intermedios de descanso desde donde se reverenciaban los wak' $a$, que se encontraban igualmente sacralizados ${ }^{2}$. En este mismo sentido votivo, en los espacios centrales de al menos 7 sitios se constataron pequeños receptáculos de piedra de forma rectangular ubicados por debajo de la superficie. Llamadas comúnmente "cajas", o " $t$ ' $и x u$ " en aymara, este tipo de estructuras continúa siendo utilizada en esta parte de los Andes para el depósito de ofrendas y de libaciones (Figura 6). Cabe mencionar también que en 4 SCC (Lakasa, San Martín, Rosapata y Cruz de Huayllamarca) se identificaron los restos de estructuras de piedras y en

2. “...los indígenas andinos no solo reverenciaron los wak'a, sino también los lugares, donde dizen que descasaron, o estuvieron las Huacas, que llaman Zamana, y a otros lugares de donde ellos las invocan, que llaman Cayan, también los reverencian”, Arriaga (1621, p. 12). 


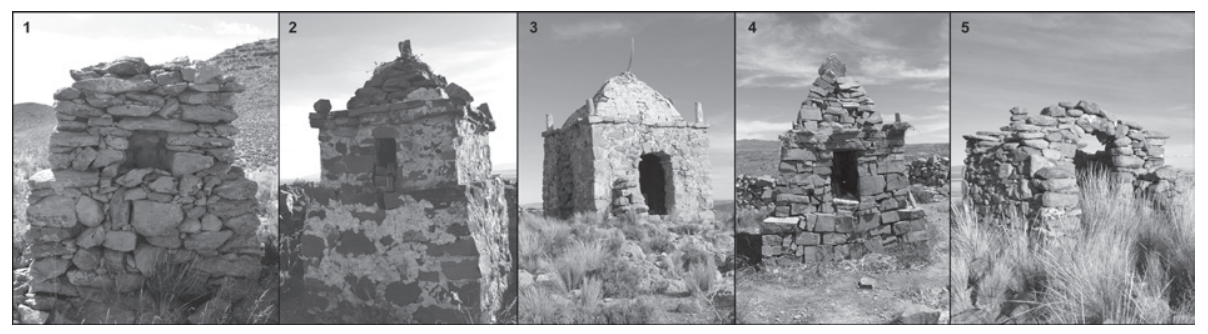

Fig. 5 - Fotografías de distintos tipos de edículos ubicados en los espacios centrales de los SCC. 1: San Martín (OrLac04), 2: Cruz de Huayllamarca (OrSuc19), 3: Orinoca (OrSuc17), 4: Yuruna Qollu

(OrSuc03), 5: Rosapata (OrSuc12) (fotos de los autores)

adobes, cuyas morfologías resultan semejantes a las tumbas prehispánicas en esos materiales que se conocen en la región.

En cuanto a los materiales que se encuentran en la superficie, en los 10 SCC estudiados con mayor detalle se registraron fragmentos de cerámicas arqueológicas. En su gran mayoría se trata de cerámicas con los estilos regionales

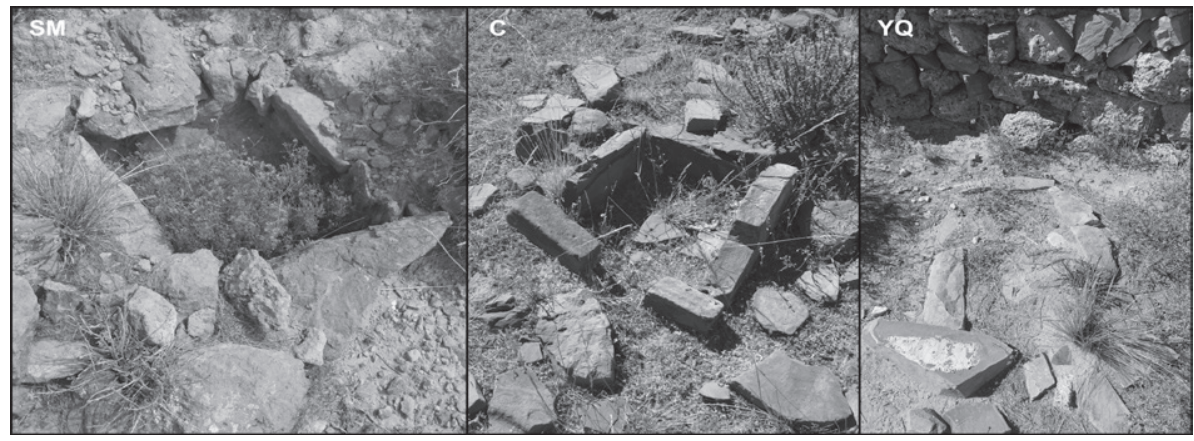

Fig. 6 - Fotografías de caja semienterradas. SM: San Martín (OrLac04), C: Corque (OrCar07), YQ: Yuruna Qollu (OrSuc03) (fotos de los autores)

conocidos como Chillpe y Quillacas, que se adscriben al Periodo de Desarrollos Regionales (siglos XI-XV) (Michel 2008; Villanueva Criales 2015). En menor medida, se identificaron también cerámicas con estilos Pacajes, Inka regional (siglos XV-XVI) y Colonial (siglos XVI-XVIII) (Figura 7a). La cantidad de estos materiales es muy variable, siendo muy alta en los SCC de Lakasa, San Martín y Orinoca. Dos aspectos de estos restos cerámicos son relevantes en tanto nos remiten a un contexto ceremonial. Por un lado, en su mayoría los fragmentos corresponden a vasijas pequeñas, pucos y platos, es decir piezas no culinarias utilizadas para el consumo colectivo de alimentos y bebidas (Bray 2003). 
Cerros, muros concéntricos y divinidades tutelares en el altiplano centro-sur andino

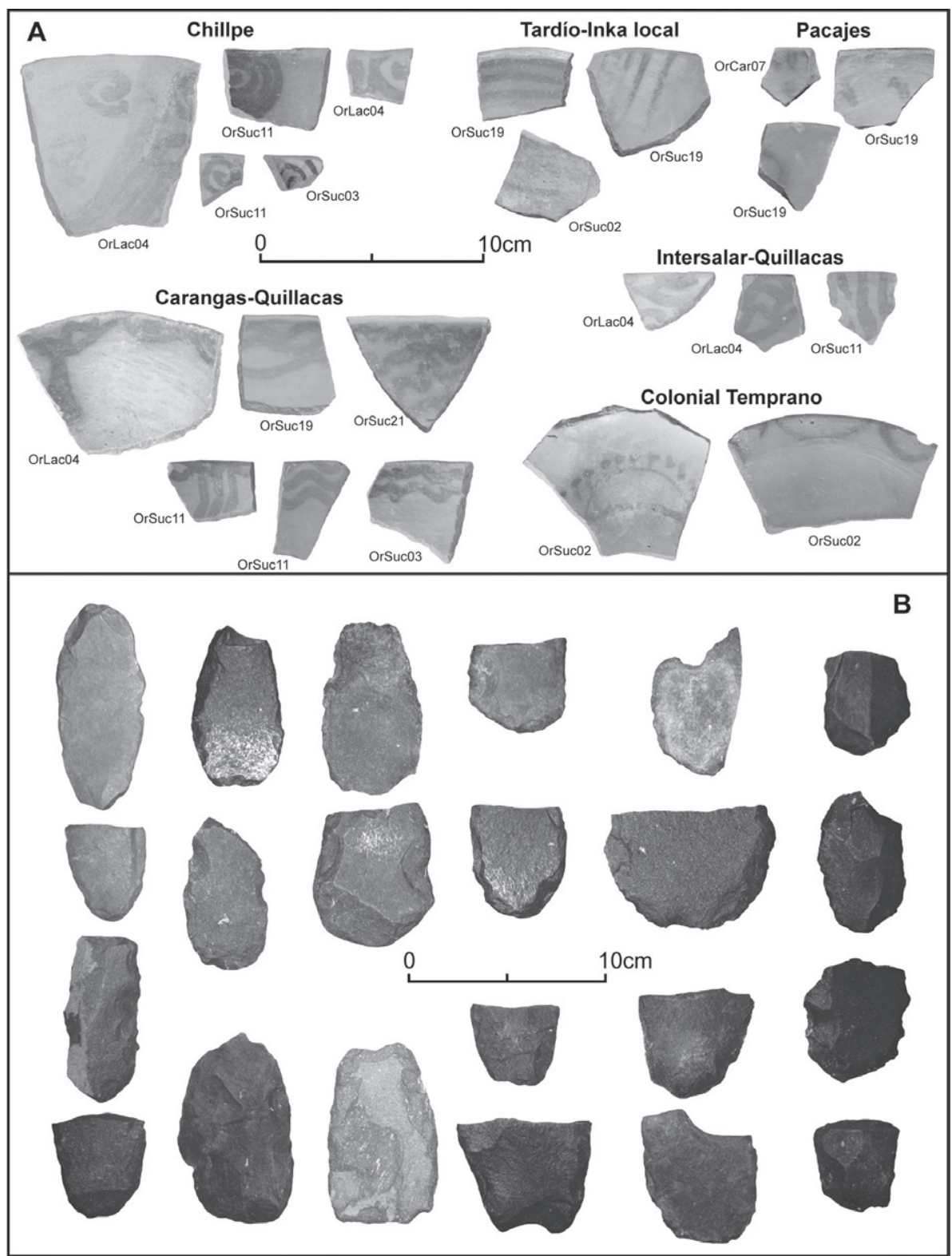

Fig. 7 - Materiales hallados sobre las superficies de los SCC: a. Fragmentos cerámicos con los principales estilos representados; b. Palas agrícolas y distintos útiles fabricados con basaltos procedentes de OrSuc11 (Orinoca; fotos de los autores) 
Por otro lado, los fragmentos cerámicos se concentran en determinados espacios de los sitios, lo que indica una sectorización de las prácticas de consumo. Junto a los fragmentos cerámicos, sobre la superficie de estos 10 SCC se encuentra también una abundante cantidad de restos líticos, principalmente basaltos negros y gris oscuro, resultantes de la fabricación de distintos tipos de palas agrícolas (chaquitacllas o taquizas) y otros útiles como cuchillos y raederas. En su mayoría se trata de lascas, piezas rotas o fallidas, y, en menor cantidad, de piezas terminadas y núcleos (Figura $7 b$ ). Como sucede con la cerámica, la cantidad y la densidad de estos materiales líticos varía de un sitio a otro, siendo notoria su abundancia en los SCC de San Martín, Orinoca, Rosapata y Corque. Por último, es de notar la recurrencia en estos sitios, y en los caminos de acceso a ellos, de reducidas acumulaciones de cantos rodados, en su mayoría con un diámetro superior a los $10 \mathrm{~cm}$, que proceden de los depósitos aluviales ubicados por debajo de los cerros con SCC.

\section{Las múltiples facetas de los wak'a locales}

Las informaciones históricas que refieren a los cultos a los wak'a locales son ciertamente menos detalladas que aquellas que trataron sobre las principales divinidades andinas, sobre todo cuando ellas se encontraban en alguna medida relacionadas con los inkas. Reunidas sobre un mismo mapa, estas informaciones conforman una extensa y difusa nebulosa de datos fragmentados. No obstante, las analogías y correspondencias simbólicas que se presentan caso por caso, incluso entre sitios geográficamente muy distanciados, muestran que los cultos a los wak'a locales fueron un fenómeno religioso generalizado y con rasgos similares. En su mayoría, estas informaciones nos fueron legadas por los clérigos que combatieron las idolatrías durante las últimas décadas del siglo XVI y las primeras del siglo XVII. Uno de ellos fue Bartolomé Álvarez, que en los años 1580 ofició como sacerdote de la doctrina de Sabaya, y posteriormente en la de Aullagas, destinos que le permitieron informarse de cerca sobre los cultos indígenas en las regiones de Carangas y Quillacas. Preocupado por la profusión de wak'a que se resistían a desaparecer en esta parte del altiplano andino, en 1588 Álvarez comentaba lo siguiente: "Y así, adoraban en la mayor parte de todos los cerros; en unos porque había uacas, en otros porque tenían memoria [de] que allí había el demonio hablado con sus pasados, o los había atemorizado; en otros por otras abusiones que el demonio había enseñado a sus pasados" (Álvarez 1998 [1588], p. 77). Al igual que varios otros curas extirpadores, Álvarez supo distinguir en el culto a los wak'a una concomitancia de diferentes escalas de sacralidad: a nivel de los poblados, de los ayllus y de las regiones. Si los wak'a mayores se encontraban anclados en el paisaje religioso en las majestuosas siluetas de las altas cumbres y volcanes, no sucedía lo mismo con muchos de los wak'a locales, que se encontraban depositados en 
Cerros, muros concéntricos y divinidades tutelares en el altiplano centro-sur andino

cerros menores, pudiendo incluso ser desplazados ${ }^{3}$. Al igual que Álvarez, en los informes de otros clérigos que combatieron los cultos indígenas en distintas partes de los Andes se resalta que la mayor parte de los wak'a locales estaban ubicados en las cercanías de los poblados, sobre la cima de cerros no muy elevados ${ }^{4}$. Tal proximidad y accesibilidad de los wak'a fue también subrayada en varios de los dibujos realizados por Guaman Poma de Ayala (1989 [1615]) y Murúa (2004 [1590]), en los cuales, fuera de toda perspectiva visual, los cerros donde se encontraban los ídolos fueron representados como diminutos promontorios. Es de notar también en estos dibujos que los wak'a se encuentran ubicados en espacios vallados o fortificados sobre la cima de los cerros (Figura 8, página siguiente). La gran mayoría de los SCC identificados concuerdan con estas características señaladas por las fuentes documentales; ellos se localizan en proximidad, o en las cercanías, de un poblado o de una estancia, sobre las cimas de colinas y cerros que en ningún caso superan los $400 \mathrm{~m}$ de altura con respecto a sus bases. Aunque poco elevados, los espacios centrales de todos los sitios poseen un amplio campo visual, y desde ellos pueden observarse a la distancia aquellos otros cerros con sitios ceremoniales semejantes, así como también las siluetas de las altas cumbres.

La presencia de concentraciones de fragmentos cerámicos en los espacios centrales de estos sitios, en su mayoría correspondientes a pucos y recipientes pequeños, estaría relacionada con prácticas de libaciones (ch'alla) y de ofrendas de alimentos colectivas, un aspecto del culto a los wak'a y de las festividades religiosas que fue ampliamente evocado por las fuentes coloniales. Al respecto, Arriaga nos cuenta que:

La principal ofrenda y la mejor, y la mayor parte de sus sacrificios, es la chicha por ella, y con ella comienzan todas las fiestas de las huacas, en ella median, y en ella acaban, sus fiestas, y ella es el todo. Y assí tienen para este efecto muchos vasos, y vasijas de diferentes formas, y materias, y es común modo de hablar, que dan de beber a las Huacas, quando les van a mochar. (Arriaga 1621, p. 24)

Cobra relevancia aquí que una parte significativa de los fragmentos cerámicos hallados en estos espacios presenten marcas de impacto. Si bien estas marcas pueden resultar de destrucciones accidentales o de los propios procesos tafonómicos, su recurrencia, y el propio contexto ceremonial de estos sitios, abre la posibilidad de que resultasen de prácticas deliberadas de "romper" recipientes cerámicos. Esto no debería sorprendernos en tanto varios estudios arqueológicos

3. "En otras partes, en cerros altos de señalada vista tenían asimismo uacas de veneración por sus provincias, y en particular cada pueblo y cada aillo, como digamos 'cognaciones' o 'parcialidades'. Tenían sus uacas todas colocadas en cerros, las cuales traían consigo y las llevaban cuando todo el pueblo se mudaba de una parte a otra buscando tierras donde vivir", Álvarez 1998 [1588], p. 75.

4. Por ejemplo, Acosta (1894 [1590]) y Hernández Príncipe (1923 [1621]). 


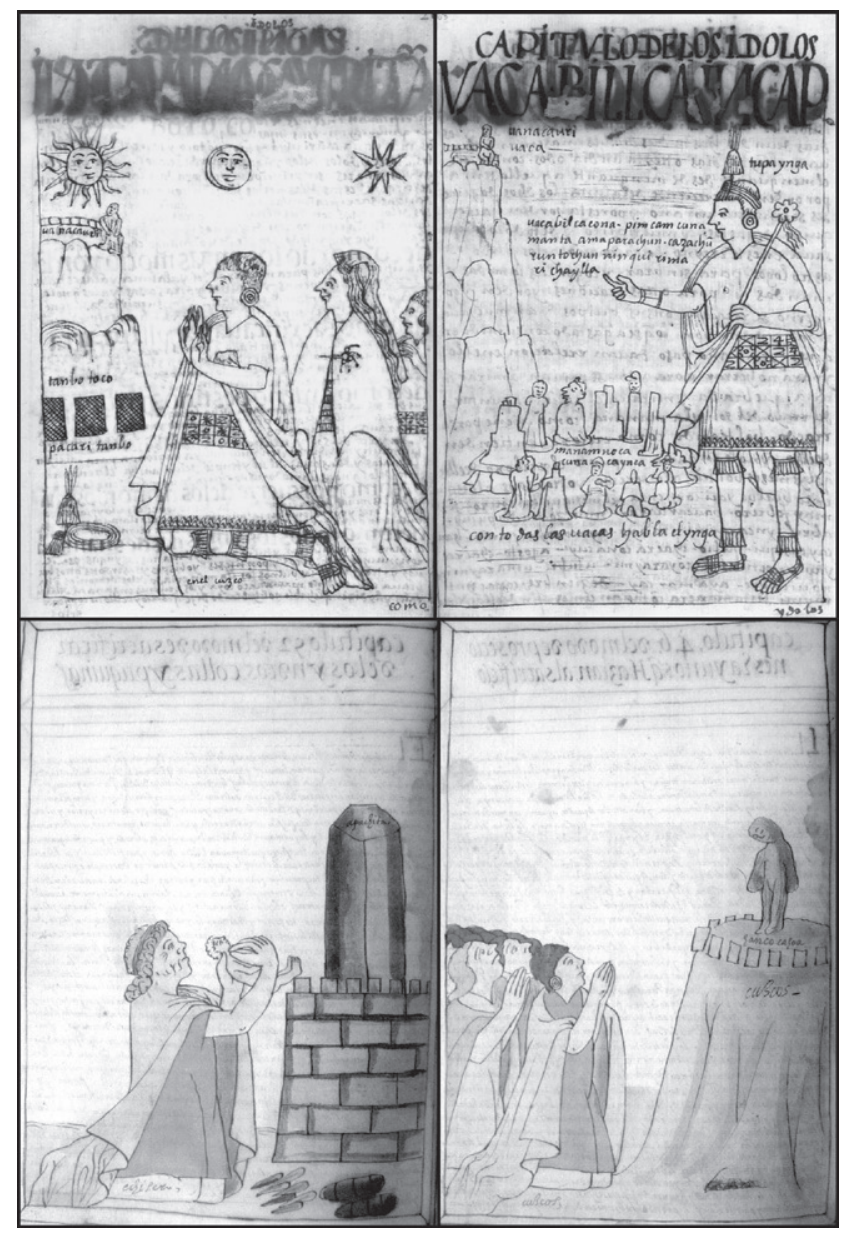

Fig. 8 - Arriba izquierda, Guaman Poma de Ayala 1989 [1615], dibujo 103, p. 266, INTI VANA CAURI TANBO TOCO. Arriba derecha, Guaman Poma de Ayala 1989 [1615], dibujo 102, p. 263, VACA WILLKA INCAP. Abajo izquierda, Murúa 2004 [1590], p. 104v, Capítulo 5.2 Del modo de sacrificar de los indios collas y puquinas. Abajo derecha, Murúa 2004 [1590], p. 98v., Capítulo 4.6 Del modo de procesionar e ayunos q̃ hazian al sacrificio (elaboración de los autores)

en sitios del altiplano boliviano refieren a prácticas de rotura intencional de cerámicas, identificadas también como "muerte de cerámicas", en contextos rituales prehispánicos ${ }^{5}$. De hecho, estas prácticas se habrían continuado incluso

5. Por ejemplo, la cerámica hallada en contextos rituales de Tiwanaku y en los pozos ofrendatorios hallados en la isla de Pariti (Korpisaari et al. 2012). 
Cerros, muros concéntricos y divinidades tutelares en el altiplano centro-sur andino

durante el Periodo Colonial, tal como pudimos apreciarlo en varios edículos vinculados, en tanto que mochaderos, con el volcán Tunupa, uno de los principales wak'a del Altiplano sur de Bolivia. No obstante, es importante tener en cuenta aquí, tal como señalara Albornoz en sus instrucciones (Duviols 1967, p. 22$)^{6}$, que la acción extirpadora llevada por la Iglesia se materializó también en la destrucción de las ofrendas cerámicas que se encontraban depositadas junto a los wak'a. Otro indicador de antiguas prácticas de libaciones y ofrendas de alimentos son las estructuras tipo "cajas" que se encuentran en los espacios centrales de varios SCC. Finalmente, otro aspecto recurrente de estos sitios es la elevada cantidad de material lítico resultante de la fabricación de palas agrícolas. Significativamente, en todos los casos se utilizó como materia prima basalto negro, que procedería de Querimita, la única cantera con estas rocas conocida para la región de Carangas (Péntek y Faragó 2019). Ubicada al sureste del lago Popóo, los basaltos negros de Querimita fueron explotados desde el Periodo Formativo, utilizándose para la fabricación de útiles agrícolas (Michel 2008, p. 78). El hecho de transportar rocas de basalto, en varios casos desde distancias considerables ${ }^{7}$, y fabricar las herramientas agrícolas en estos espacios ceremoniales podría estar relacionado con el rol que tuvieron los wak'a locales en la producción agrícola. Por las citadas fuentes coloniales sabemos que, al igual que las divinidades mayores, muchos de los wak'a locales tuvieron sus propios espacios agrícolas, que eran igualmente reverenciados, siendo los primeros en ser labrados y $\operatorname{cosechados}^{8}$. Es importante tener en cuenta aquí que estos wak'a podrían ser también huancas, ancestros o antepasados litificados (Duviols 1979), considerados como los señores y protectores de las chácaras. En este sentido, es relevante que en la mayoría de los 135 sitios registrados los cercados concéntricos delimitan distintos niveles de superficies aterrazadas que fueron utilizadas, y en varios casos continúan siendo usadas, como parcelas de cultivo (Figura 9, página siguiente).

Ahora bien, la cantidad y distribución de estos sitios, incluyendo aquellos identificados en imágenes satelitales al norte del área de estudio, indica que se trataría de un fenómeno generalizado y particular a la meseta altiplánica central, no registrando casos semejantes en las vecinas zonas de cordillera y valles, así como tampoco en el altiplano surandino. Los procesos sociales que tuvieron

6. "Asimismo ha(se) de tirar y destruir todos los basos antiguos que tienen con figuras y mandar que nos hagan ningunos en la dicha forma porque se les rrepresenta en tolas las fiestas que hazen todo lo antiguo y para eso los tienen", Cristóbal de Albornoz [1581], en Duviols (1967, p. 22).

7. Si la cantera de Querimita se ubica a $8 \mathrm{~km}$ de Rosapata y a $10 \mathrm{~km}$ de Orinoca, ella se distancia de $72 \mathrm{~km}$ de San Martín, de $75 \mathrm{~km}$ de Cruz de Huayllamarka y de $81 \mathrm{~km}$ de Corque.

8. Por ejemplo, Arriaga (1621, p. 24) nos cuenta que: "En la sierra se haze unas veces del maíz que se siembra la Huaca, y es la primera chácara, o sementera que se labra, y ningún indio puede sembrar antes, que se siembre esta chácara". 


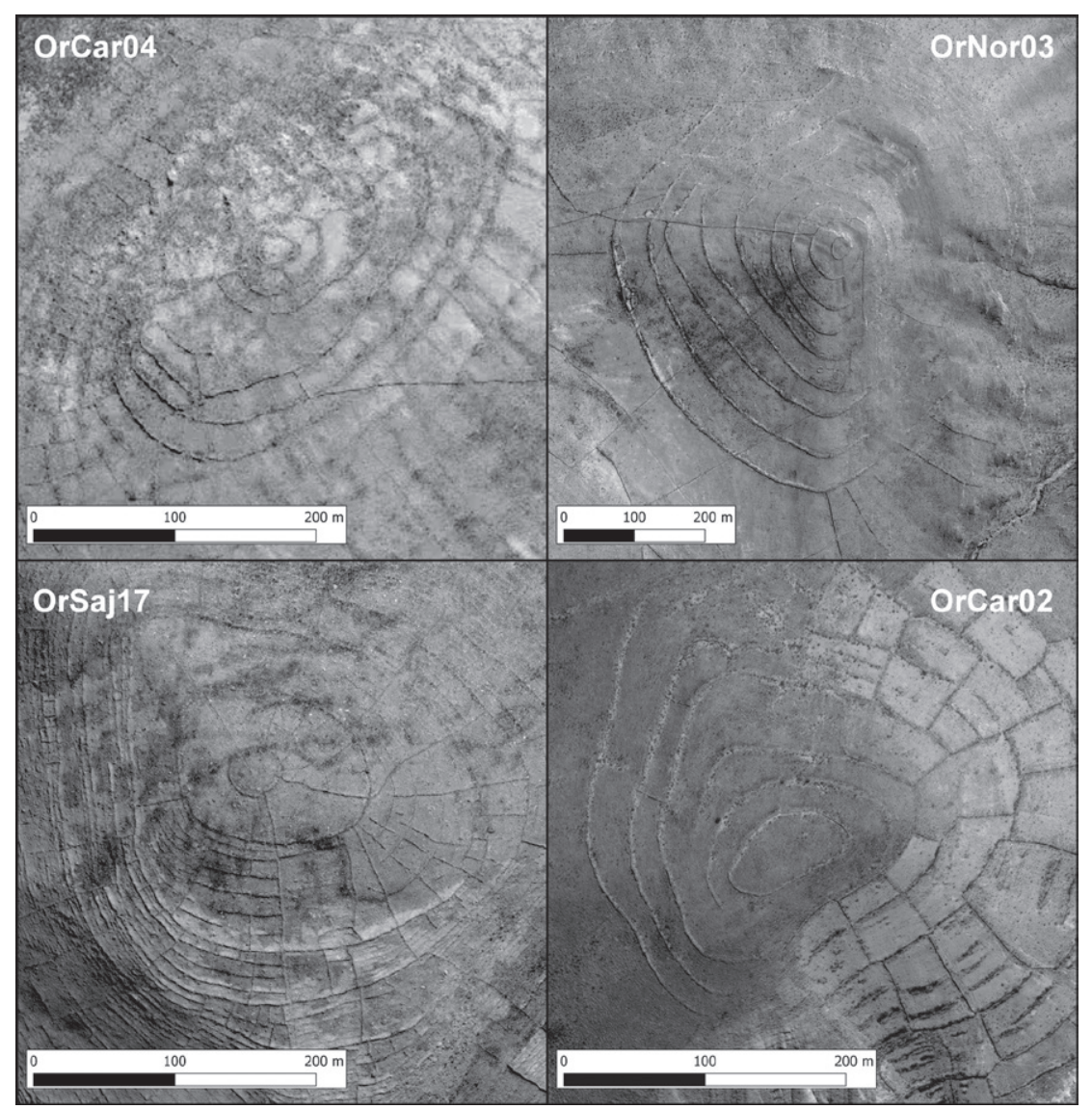

Fig. 9 - Imágenes satelitales de 4 SCC en los que se observan distintos tipos de superficies agrícolas ubicadas entre los muros concéntricos (elaboracion de los autores; fuentes: Geoeyes, Digital Globe, Google Earth)

lugar en este amplio espacio desde comienzos del Periodo de Desarrollos Regionales (siglos XII-XV) llevaron a la formación de distintas configuraciones territoriales, que se conocen en la historiografía como naciones o señoríos aymaras; de norte a sur: qollas, lupaqas, pacajes, carangas y quillacas (BouysseCassagne 1987). Estas sociedades que antecedieron a los inkas compartieron una semejante economía agropastoril adaptada a las rudas condiciones ambientales del altiplano. Según varias fuentes, sabemos que estas sociedades se integraron regionalmente formando una confederación de naciones, en la que se sumaron también otras configuraciones regionales, tales como los qaraqaras, charkas, soras y chichas (Platt, Bouysse-Cassagne y Harris 2006). Además de integrar esta confederación, estudios etnolingüísticos relativamente recientes proponen 
que estas sociedades habrían compartido una misma lengua, el pukina, siendo esta posteriormente reemplazada por el aymara (Bouysse-Cassagne 2010).

Es importante señalar, sin embargo, que sitios similares a los aquí tratados fueron identificados también en varias otras partes de los Andes, y que se interpretaron igualmente como espacios ceremoniales y/o relacionados con los antiguos cultos a los wak'a. Mientras que en algunas regiones estos sitios fueron cronológicamente adscritos al Periodo de Desarrollos Regionales o Intermedio Tardío, en otras se vincularían con los inkas. Por ejemplo, sitios ceremoniales preinkaicos con muros concéntricos (concentrics walls) muy similares a los observados en el Altiplano central fueron registrados en las regiones de Huaura, Chankay y Lima en la costa central de Perú (Guzmán García 2007; Dalen Luna 2012, entre varios otros), y en la región de Ankash en la Sierra Central del Perú (Orsini y Benozzi 2016). De la misma manera, en la cima de varios cerros cercanos a la localidad de Ollantaytambo, al norte del Cuzco, se encuentran distintos espacios ceremoniales con aterrazamientos y plataformas concéntricas que los inkas erigieron, en su dinámica de conquista ritual (Nielsen y Walker 1999), sobre anteriores ocupaciones locales (Kosiba y Galiano Blanco 2013). Espacios ceremoniales con características semejantes, e igualmente vinculados con la expansión territorial de los inkas, se encuentran en distintas regiones de los Andes. Entre otros ejemplos se encuentran el sitio ubicado sobre la cumbre del cerro San Cristóbal en la región de Huarochirí (Chase 2015), y aquellos ubicados en los cerros Llamoq y Wiñaj en Ankash (Ibarra Asencios 2016). Se destacan también varios sitios con murallas y plataformas concéntricas y/o espiraladas situadas sobre las cimas de cerros de las regiones de Cuenca, Chimborazo, Riobamba y Pichincha en la Sierra Central de Ecuador (Aguirre Merino 2015).

\section{Los asientos de los wak'a}

Ciertamente los SCC aquí tratados muestran semejanzas formales con los asentamientos prehispánicos que se ubican en las laderas y en las cimas de los cerros que se identifican, en una gran parte de los Andes, bajo el término de pukara. Si bien la presencia de fortificaciones no es una condición sine qua non de los pukaras andinos, toda ocupación prehispánica ubicada en las partes altas de los cerros y que posea murallas defensivas es generalmente considerada, por antonomasia, como un pukara. De hecho, esta palabra aparece en el nombre de varios cerros que tienen un SCC en sus cimas, tal el caso de "Pukara Qullu" en Yuruna (OrSuc02), o es utilizada vernáculamente para resaltar esta condición, por ejemplo "el pukara de Orinoca" (OrSuc17). Si bien su traducción más inmediata es la de fortaleza, el término se integra en un campo de significación que sobrepasa la condición meramente defensiva. Es interesante aquí la amplitud semántica que tiene la palabra pukara en sus primeras traducciones. 
En el vocabulario aymara de Bertonio (1984 [1612]), "pucara" es traducido como fortaleza, castillo y refugio, siendo metafóricamente usado también para señalar una población o concentración de "cosas" poco visibles o escondidas, por ejemplo, la infestación de piojos (lappa) o de pulgas (sutti). En cambio, en las traducciones del léxico quechua de González de Holguín (1952 [1608]), "pucara" designa una fortaleza, castillo, muralla o guarida en un sentido más defensivo y militar, siendo relevante su vinculación con los inkas, y particularmente con la existencia, dentro de la estructura estatal, de un cargo de custodia o administración: los pucaras camayoc. El acento militar de la traducción al español de esta palabra se encuentra en sintonía con la caracterización dada a estos sitios preinkaicos en las fuentes coloniales, sobre todo en aquellas redactadas durante las primeras décadas del siglo XVII. En estos escritos, cuyas narrativas ensalzaron el carácter civilizador que tuvieron los inkas con respecto a los pueblos que les precedieron y sometieron, los pukara aparecen como fortalezas militares relacionadas con los awqa runa (hombre de guerra) o el awqa pacha (época o edad de guerra), un periodo de tiempo marcado por una inestabilidad endémica y por constantes conflictos bélicos (entre otros Guaman Poma de Ayala 1989 [1615], p. 63) ${ }^{9}$. Sin embargo, al referirse al pukara de Ayaviri, y sin contradecir su función defensiva, Vázquez de Espinosa (1948 [1629], p. 559) nos dice que el término "quiere decir lugar fuerte, donde uvo grandes, y souerbios edificios en los quales auia muchos bultos de piedra, de figuras de hombres y otros animales muy curiosamente acabados". Es importante señalar aquí, en este mismo sentido, que los estudios arqueológicos vienen enfatizando cada vez más el carácter multifuncional de los pukaras habitacionales, siendo identificados en varios casos espacios ceremoniales y estructuras religiosas y/o funerarias (p.e. Tarragó 2011; Arkush 2012, entre otros).

La connotación religiosa del término pukara se mantuvo hasta nuestros días en tanto la palabra es todavía usada para designar algunos espacios sacralizados, las divinidades tutelares que los habitan y determinados tipos de ofrendas. Tal como lo señalara G. Martínez (1983, p. 89) en el altiplano aymara del norte de Chile y de Bolivia, bajo el término pukara se identifican los lugares sagrados de cada estancia que se relacionan con los cultos agrícolas. Más aún, en la región de Isluga, en el norte de Chile, las divinidades que se asocian con estos espacios ceremoniales, que pueden o no estar ubicados en sitios arqueológicos, son llamadas pucar mallku (masc.) y pukar t'alla (fem.) (Martínez G. 1976, p. 279-282). Los nombres de estas deidades tutelares dan cuenta de la relevancia y fluidez semántica que posee el término, actuando al mismo tiempo como una categoría del espacio religioso y como un determinado tipo de entidad no-humana que

9. Por ejemplo en Guaman Poma de Ayala (1989 [1615], p. 64): "Estos dichos yndios se sallieron y se despoblaron de los dichos buenos citios de temor de la guerra y alsamiento y contradición que tenían entre ellos. De sus pueblos de tierra baja se fueron a poblarse en altos y serros y peñas y por defenderse y comensaron a hazer fortalezas que ellos les llaman pucara". 
habita en ellos. Finalmente, cabe señalar que, relacionado igualmente con los ritos de fertilidad agrícola, en la región de Tarabuco (Chuquisaca, Bolivia), se llama pukara a un altar en forma de escalera que se fabrica cada año durante el carnaval (pujllay), y que se encuentra ornamentado con flores y con toda clase de alimentos (Martínez R. 2010, p. 146). Es en esta polisemia del término pukara que se inscriben los SCC aquí tratados, diferenciándose de los poblados fortificados principalmente por su condición religiosa y ceremonial ${ }^{10}$. En este sentido, los SCC se presentan como arquetipos o contraparte sacralizada de los pukaras habitacionales, emplazamientos estructural y simbólicamente fortificados destinados a albergar a los wak'a locales. Es importante señalar aquí, sin embargo, que al menos $6 \mathrm{SCC}$, que representan apenas un 4,4\% del total, se encuentran ubicados por encima, en el mismo cerro o colina, de un pukara habitacional, estando siempre ambos contextos claramente definidos y separados. Tal es el caso, por ejemplo, del SCC que se encuentra en Lakasa (OrLac05) en la región Intersalar, que significativamente muestra una ocupación distinta a la del pukara habitacional que se encuentra por debajo de este.

No son pocas las referencias en las fuentes coloniales al hecho de que los espacios en las cimas de los cerros donde descansaban los wak'a locales eran fortalezas. Por ejemplo, Hernández Príncipe (1923 [1621], p. 30-55) nos cuenta que el wak'a llamado Apuyuric del Ayllo Híchoc estaba en "un peñol de más de cuadra de largo a modo de fortaleza", y el wak'a llamado Llásac del pueblo de Urcón se encontraba en un asiento "con cantería, a modo de fortaleza", mientras su hijo, el wak'a Yallpu Huallanca, se ubicaba en un "corralón". Un ejemplo gráfico que subraya la condición de fortaleza de estos espacios ceremoniales aparece en uno de los dibujos de Murúa (2004 [1590], p. 104v.) que refiere, precisamente, a las idolatrías de los indios collas y puquinas del Altiplano central. El dibujo nos muestra a una hechicera ofreciendo en sacrificio a un niño a lo que él identifica como "apacheta", una roca erguida más cercana a nuestra idea de wak'a y de huanca (Figura 8), que se encuentran en el interior de una fortificación de piedra claramente inspirada en los "donjon" de los castillos medievales europeos. El hecho de que varios de los wak' locales se encontraran en espacios fortificados ubicados en las cimas de cerros y de promontorios tampoco debería resultarnos extraño. En tanto divinidades tutelares, y con frecuencia también ancestros fundacionales, los wak'a locales desempeñaron un papel crucial en la reproducción social y económica de cada comunidad. Como el jesuita Arriaga, varias fuentes coloniales dieron cuenta de lo esencial que resultaba para los pueblos andinos proteger y mantener satisfechos a sus $w a k$ 'a con el fin de garantizar el éxito de sus cultivos y la prosperidad y tranquilidad de sus comunidades. Sabemos también que, contrariamente,

10. De manera significativa, la ausencia de mayores estructuras habitacionales en algunos SCC de Carangas condujo a que estos fueran identificados como pukaras "escasamente habitados" o "sin población" (Villanueva Criales 2015), o bien, "pukaras rituales" (Lima 2012, p. 66). 
el despojo o la destrucción de los wak'a locales era vivido como una catástrofe cósmica irreversible, que podía incluso llevar a la desaparición de las mismas poblaciones. De suerte que los wak'a locales, de los cuales dependían el destino de los pueblos indígenas, eran también uno de sus puntos más vulnerables, algo que tanto los inkas, como más tarde los españoles, conocieron y supieron aprovechar. Pero no solo eso, la potencial eficacia simbólica que tuvieron estos wak'a hizo que fueran también, tal como lo señalan Bouysse-Cassagne y Chacama (2012, p. 675), objetos de envidias y robos en contiendas rituales.

Así y todo, los sitios con cercos concéntricos no habrían respondido solamente a esta lógica defensiva. Independientemente de su grado de circularidad o de regularidad, el hecho de que los cercos se encuentren dispuestos de manera concéntrica resalta el carácter de "taypi" (centro) de, valga la redundancia, los espacios centrales. La palabra aymara taypi designa lo que se encuentra en el medio o en el centro de las cosas; en el ámbito de la religión, se trata de un centro primordial y ordenador del que depende el equilibrio del mundo (Bouysse-Cassagne 1978, p. 1065). La condición de taypi de los SCC se expresa en dos planos simultáneos y complementarios. Por un lado, estos sitios se remarcan visualmente en el paisaje, muchos de ellos incluso a varios kilómetros de distancia, ya sea por los mismos cercos o murallas, por los caminos que conducen a sus cimas, o por el contorno aterrazado que poseen algunas colinas, tal el citado caso de Rosapata. Por otro lado, a través de la experiencia que implicaba el circular por varios niveles, ya sea a través de caminos rectilíneos y escalonados o pasando por las rampas que comunican distintos niveles hasta alcanzar los espacios centrales. La existencia de varias etapas que anteceden los espacios centrales de culto, el sanctasanctórum en términos bíblicos, fue también un atributo de los wak'a mayores y principales centros religiosos andinos. Por ejemplo, Ramos Gavilán (1976 [1621], p. 48-49) nos cuenta que para acceder al templo y wak'a del Sol en el Titicaca era necesario primero pasar por tres portales, distantes entre sí de tan solo 20 pasos, cada uno implicando una etapa de purificación requerida para acceder al wak'a.

El principio de taypi evocado por los SCC se corresponde al mismo tiempo con la condición de paqarina que, según nos señalan las fuentes, tuvieron numerosos wak'a locales. De manera general, las paqarinas eran consideradas como lugares de origen, surgiendo de ellas los ancestros de cada pueblo, ayllu o nación, siendo muchas veces representado por un wak'a fundacional, una huanca, como también un río, una vertiente, una cueva, un árbol, o una tumba ${ }^{11}$. Por ejemplo, el wak'a de Llásac citado anteriormente, que se encontraba ubicado

11. Por ejemplo, Arriaga (1621, p. 40) refiere a las pacarinas en los siguientes términos: "y así [los indios] están persuadidos no sólo que los Españoles proceden de un principio, y los negros de otro, sino que cada Ayllo, y parcialidad de los Indios tiene su principio y Pacarina, que ellos llaman particular, y la nombran, y la adoran, y ofrecen sacrificio; 
en una "fortaleza" en la cima de un cerro, era la paqarina del pueblo de Urcón ${ }^{12}$. No obstante, resulta aquí muy sugestivo el planteamiento de Martínez Cereceda (2004, p. 510) acerca de pensar las paqarinas andinas no solo como lugares de surgimiento, sino también como espacios de llegada, hitos fundacionales para aquellas poblaciones que se asentaron y formaron comunidad y un territorio en un determinado lugar.

\section{Wak'a, thaki y marka qullu}

Los restos cerámicos observados en los SCC se adscriben en su gran mayoría al periodo prehispánico conocido como Desarrollos Regionales Tardíos (siglos XIII$\mathrm{XV}$ ). Por tanto, estos espacios ceremoniales continuaron funcionando durante los periodos posteriores. Si bien los restos de cerámicas con estilos inkaicos, o vinculados con su expansión meridional -como la cerámica Pacajes-, son poco abundantes en estos sitios, varios de ellos poseen un rasgo estructural que sugiere su adopción por parte de los inkas. Esto no debería sorprendernos en tanto que, durante su expansión territorial, los inkas fueron reconociendo e incorporando en su universo religioso las divinidades locales y sus respectivos lugares de culto. Se trata de aquellos SCC que poseen un camino que conduce directamente a sus espacios centrales, los cuales tienen un trayecto rectilíneo muy regular, con frecuencia con tramos empedrados y largas escalinatas de piedra, características que son distintivas del tramado vial inkaico (Figura 10, página siguiente). Es de notar también que los inkas erigieron, en distintas partes de los Andes e igualmente sobre la cima de colinas no muy elevadas, espacios ceremoniales con caminos de acceso semejantes a los observados en los SCC del altiplano. Por ejemplo, en el centro administrativo y ceremonial inkaico de Shincal de Quimivil (Catamarca, Argentina), uno de los principales espacios ceremoniales se encuentra ubicado sobre la cima de una pequeña colina, aterrazada a modo de plataforma, a la cual se accede por una larga y recta escalinata de piedras (Raffino 2004 y ss.). En sentido contrario, esta escalinata se proyecta directamente hacia la plaza central del sitio (awkaypata) donde se encuentra el ushnu.

llamándola Cámac, que es Criador, y cada uno dize que tiene su Criador, unos dizen que tal Cerro, otros que de tal fuente, otros qüentan de sus Pacarines muchas fábulas y patrañas".

12. "La pacarina y origen destos de quien se jataban proceder, es Llásac, su huaca: finjen que viniendo por la Cordillera llegó a descansar a un alto cerro llamado Choque Cayan; y éste, después de haber tenido los hijos que diremos, se convirtió en piedra, la cual dicen quemó fray Francisco y yendo a su simulacro la halló soterrada en pedazos acompañada de idolillos que tornaron los indios a poner después de su quema por edicto de aquel cacique apóstata y le habían adorado de nuevo. Este asiento está con cantería, a modo de fortaleza, arriba del pueblo de Urcon”, Hernández Príncipe (1923 [1621], p. 55). 


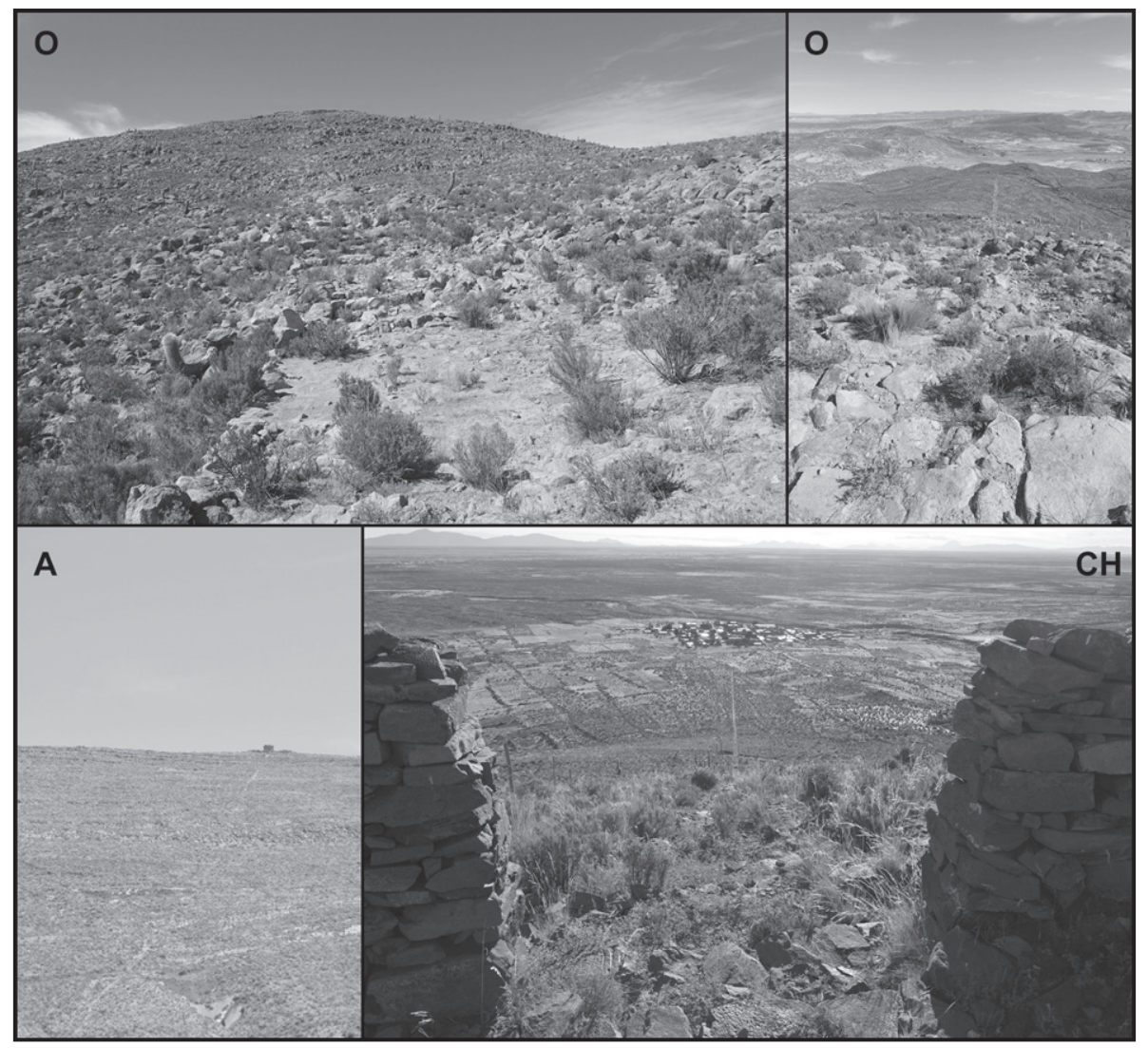

Fig. 10 - Fotografías de los caminos rectilíneos y con graderías que conducen a los espacios centrales de los SCC. O: Orinoca (OrSuc17), A: Avaroa de Andamarca (OrSuc06), CH: Cruz de Huayllamarca (OrSuc19) (fotos de los autores)

En los casos de los SCC, los caminos rectilíneos comunican en su mayoría con poblados actuales. No obstante, estas localidades, al igual que los SCC, poseen una larga temporalidad, habiendo sido varias de ellas pueblos de reducción durante el Periodo Colonial ${ }^{13}$. Pero estos caminos no solo fueron vías de acceso a los SCC, sino componentes estructurales de un mismo complejo ceremonial, siendo muy probablemente los recintos circulares ubicados junto a ellos otros testimonios de esta condición. Cobra relevancia aquí lo que señalara Albornoz (Duviols 1967, p. 38) acerca de que la mayoría de los wak'a tenían sus propios

13. Por ejemplo, Sabaya, Orinoca, Andamarca, Turco, Huachacalla, Colquemarca y Pampa Aullagas. 
Cerros, muros concéntricos y divinidades tutelares en el altiplano centro-sur andino

"ceques o cachauis" en los que igualmente se realizaban ofrendas ${ }^{14}$. De hecho, de la misma manera que la plataforma con escalinata de Shincal de Quimivil, muchos de estos caminos rectilíneos comunican los espacios centrales de los SCC con las plazas centrales de las localidades con ellos vinculadas. Este patrón recurrente subraya el rol que tuvieron estos sitios en la estructuración simbólica del espacio. En este sentido, Gilles Rivière (1982, p. 164-168) precisa que, en la localidad de Sabaya, el largo y rectilíneo camino llamado Wirgin Takhi (camino de la Virgen), que vincula el Pusi Suyu ubicado sobre la cima del cerro Pumiri, con la plaza central del pueblo, forma un eje que determina el linde entre las “moitiés" aransaya y urinsaya del territorio (marka) ${ }^{15}$. El Pusi Suyu del cerro Pumiri, un espacio sagrado principal (ibid., p. 164) en donde se concentran distintos edículos y estructuras ceremoniales, se encuentra delimitado solamente por un muro perimetral. Si bien esta característica del Pusi Suyu lo diferencia de los SCC aquí tratados, este se integra dentro de la misma categoría de hito religioso. En efecto, además de delimitar las parcialidades aransaya y urinsaya de la marka de Sabaya, el Pusi Suyu es el centro donde se cruzan dos ejes simbólicos en forma de X cuyos extremos están marcados por cuatros SCC ubicados en lados contrarios del cerro Pumiri. Un primer eje sigue la trayectoria del Wirgin Thaki, teniendo en un extremo (sureste) el sitio OrSab18 ${ }^{16}$, llamado "silo Candelaria", y en el otro (noroeste) el sitio OrSab08. Por su parte, el otro eje está conformado por los sitios OrSab09 (suroeste) y OrSab06 (noreste) (Figura 11, página siguiente). El hecho de que ambos ejes se crucen precisamente en el Pusi Suyu demuestra que la ubicación de los cuatro SCC respondió a una voluntad deliberada en función de este espacio sagrado primordial.

Por último, no se puede obviar la relación que existe entre los caminos rectilíneos de los SCC con un rasgo distintivo -y aún poco estudiado-, de las laderas del volcán Sajama (6542 m), principal apu y wak'a de la región de Carangas, presente igualmente en las vecinas montañas Asu Asuni (5088 m) y Anallajsi (5750 m). Conocidas como "líneas" del Sajama o de Carangas, las laderas bajas de estas montañas se encuentran marcadas por una multitud de caminos y senderos ascendentes de trayecto marcadamente rectilíneo. Estos fueron interpretados como caminos rituales o "ceques" relacionados con los cultos

14. “[...] todas las más guacas que están en los cerros y en llanos, tienen alrededor de si unas señales que llaman cachauis, que son señales de los ofrescimientos que a las tales guacas hazian y tienen sus nombres en nombre cada serial del que allí ofresció hijo o carnero de oro o plata o de mollo. Hallarán los ofrescimientos en los tales ceques o cachauis. Es necesario destruirlos juntamente con las guacas y con todo el cuidado".

15. El nombre aymara de Pusi Suyu se traduce del aymara como "cuatro sectores o territorios", lo que nos remite directamente a los cuatro cuartos en que se encontraba organizado el imperio de los inkas, el Tawantinsuyo (Rivière 1982, p. 163).

16. Este sitio se encuentra al lado y por encima del camino Wirgin Thaki, que recorre el talweg de la quebrada en dirección a la plaza del pueblo. 


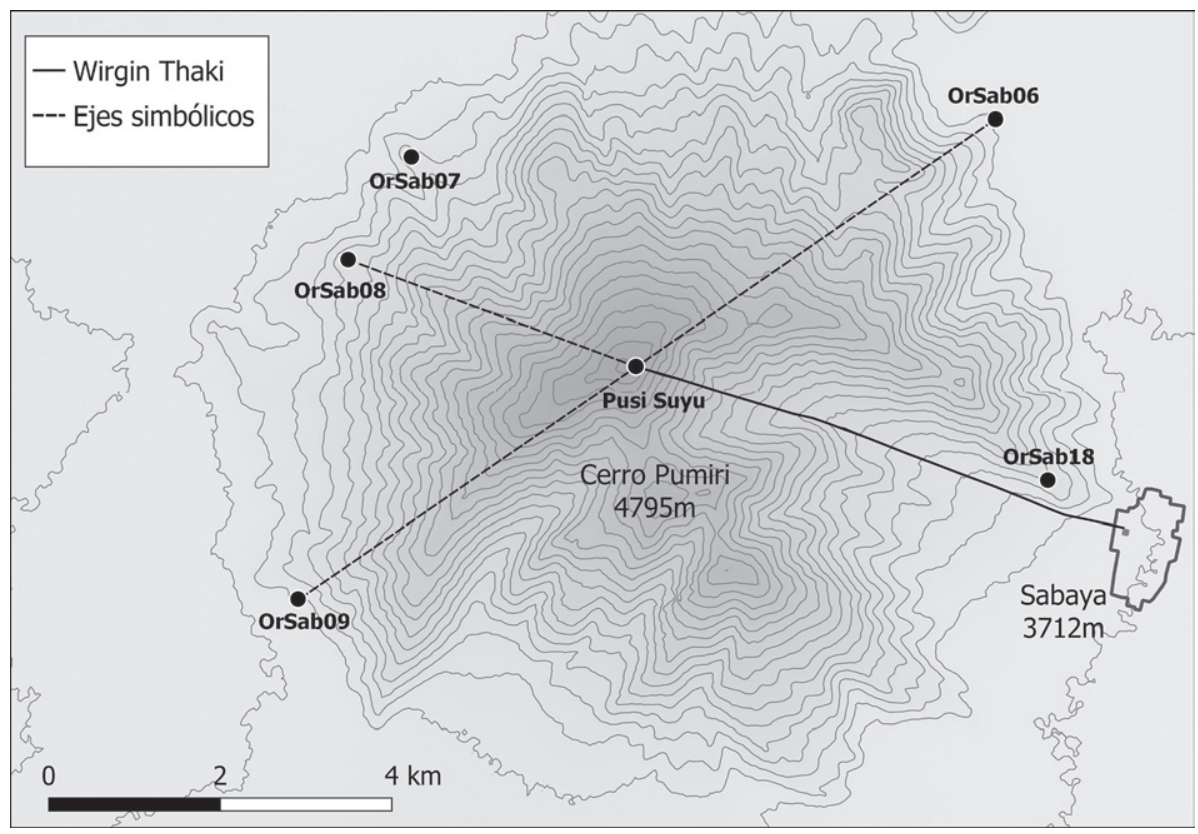

Fig. 11 - Plano del cerro Pumiri en Sabaya mostrado en Wirgin Thakhi y los ejes simbólicos que comunican los SCC con el Pusi Suyu (elaboración P. Cruz)

a los cerros-wak'a principales, siendo también asociadas con la presencia inka en la región (Michel 1999). Si una gran parte de estos trayectos rituales tienen su comienzo en poblados y en pequeñas estancias, otra parte lo hace en espacios totalmente deshabitados, con frecuencia marcados por una pequeña capilla o un edículo (torres, capillas-pozas) semejante a los que se encuentran en los espacios centrales de los SCC. Por su parte, y salvo contados casos, la totalidad de estos caminos desemboca en espacios igualmente despoblados en las laderas, muchos de ellos también marcados por un edículo (Figura 12). De manera significativa, al pie de estas montañas se encuentran varios SCC, sobresaliendo entre ellos Changamoco, situado en la falda sur del Sajama, considerado por Gisbert (1994, p. 481) como un importante wak'a regional. $\mathrm{Y}$ en efecto, por debajo de este sitio con cercos concéntricos se encuentra una importante pared rocosa en la que se labraron varios conjuntos de nichos de distintos tamaños y formas. Las bases planas de estos nichos sugieren que estos fueron labrados en la roca para contener objetos y/o restos materiales adscritos en el ámbito de la religiosidad (p.e. vasijas, queros, efigies, conopas, cuerpos momificados, etc. $)^{17}$.

17. A pocos kilómetros de Ollaytatambo se encuentra Ñaupa Iglesia, un sitio ceremonial inkaico con arquitectura lapidaria similar a la observada en Changamoco. De manera 
Cerros, muros concéntricos y divinidades tutelares en el altiplano centro-sur andino

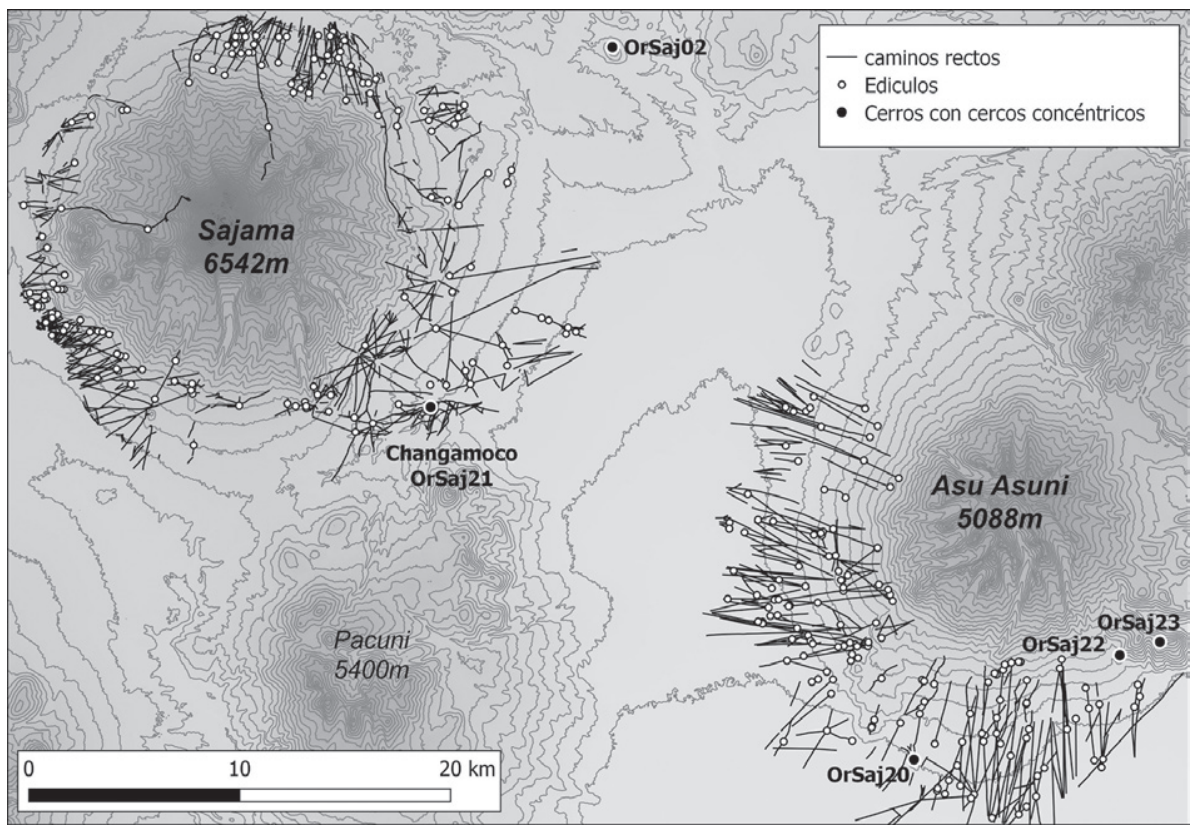

Fig. 12 - Cartografía de los senderos rectilíneos y edículos que se encuentran en las laderas de las montañas Sajama y Asu Asuni. Estos fueron identificados a partir de imágenes satelitales de alta resolución

(0.4m/px, DigitalGlobe, CNES, AIRBUS; Geoeyes) (elaboración P. Cruz)

Ahora bien, ya sea que conduzcan a los espacios centrales de los SCC o que se vinculen con los cerros-wak'a principales, el hecho de transitar por estos caminos, senderos y escalinatas fue parte entera -y en muchos casos aún continúa siéndolo- de las propias experiencias religiosas. Cobra relevancia también aquí la polisemia del término aymara thaki, que refiere tanto a los caminos pedestres como a los recorridos o a las etapas de la vida y a todas aquellas prácticas en donde se construyen y se reproducen las explicaciones ontológicas acerca del mundo y de la memoria social de las comunidades (Abercrombie 1998). De hecho, la mayoría de estos sitios ceremoniales y formaciones geológicas ocupan hoy en día un lugar central en las narrativas ontológicas que cimientan las comunidades de esta parte de los Andes. En algunos casos, como en Sabaya, ellos fueron escenarios donde tuvieron lugar eventos religiosos fundacionales, muchas veces vinculados con una divinidad tutelar. En otros casos, como en Rosapata, remiten a una temporalidad mítica en la que los cerros y las montañas

significativa, este sitio se integra en un paisaje ritualizado marcado por espacios ceremoniales ubicados en las cimas de los cerros (Kosiba 2015), que presentan terrazas y amurallamientos concéntricos semejantes a los SCC del altiplano. 
eran personas que, al igual que los humanos, podían desplazarse, relacionarse entre sí, mantener relaciones sexuales y reproducirse. Por tanto, estos sitios no son considerados como espacios fosilizados o monumentos rememorativos, sino como entidades que mantienen vigentes sus capacidades de agencia y de mediación, tanto sobre los humanos y demás seres vivos, como sobre los fenómenos meteorológicos y las divinidades mayores. Por tal razón la mayoría de estos SCC continúan funcionando como espacios primordiales para las prácticas religiosas colectivas. Así, cada 30 de noviembre, para San Andrés, los comunarios de Rosapata ascienden a la cima del cerro Gloriapata para realizar sus "costumbres" ancestrales. Lo mismo sucede ese mismo día en Orinoca, Yuruna, Cruz de Huayllamarca, Belén, Andamarca, Corque, Pampa Aullagas, y en muchos otros pueblos y comunidades campesinas del altiplano boliviano. Estas costumbres se realizan cada año para agradecer y pedir la protección y la providencia de los cerros tutelares y de la Pachamama. Ellas tienen también la finalidad de predecir cómo será el clima, convocar a las lluvias y repeler la amenaza de los granizos. Estas ceremonias comprenden una wilancha, el sacrificio de una llama blanca, con frecuencia también un cordero blanco, la ch 'alla, libaciones de chicha y alcohol, la ofrenda de abundantes alimentos, y la preparación y entrega de mesas rituales. Por otra parte, Gilles Rivière (com. pers., 2020) nos cuenta acerca de otra práctica ritual que tiene lugar en estos espacios ceremoniales del altiplano. Entre las "costumbres" que se realizan en el Pusi Suyu de Sabaya se encuentra la "barratilla", que consiste en un juego de rol o representación colectiva en la que los participantes venden simbólicamente distintos "productos" (piedras, plantas, etc.). La barratilla del Pusi Suyu tiene lugar en un espacio delimitado por un muro circular de piedra, y las monedas de cambio que se utilizan en las transacciones simbólicas no son otras que los fragmentos de cerámicas arqueológicas que se encuentran diseminadas sobre la superficie del sitio. La venta exitosa de los productos ofrecidos se traduce en un buen año para las actividades económicas de cada participante. Concluida esta práctica ritual, que se vincula igualmente con la fertilidad, todos los fragmentos cerámicos son "devueltos" dado que, en ningún caso, deben salir del sitio. Es por esta razón que en el SCC de Cruz de Huayllamarca (OrSuc19) los fragmentos de cerámicas arqueológicas se encuentran cuidadosamente depositados en el interior de nichos ubicados en la pared de piedra que delimita el espacio central del SCC.

Otras ceremonias invocan a los cerros tutelares para que intermedien, ya sea llamando a las lluvias o regulando los fenómenos atmosféricos. Al respecto, Fernández Juárez (2002, p. 63) recoge en la región de Omasuyos una interesante descripción de los ritos de pago ofrecidos a los cerros tutelares con el fin de que ellos conformen una "barrera simbólica" que frene la amenaza del granizo. En las palabras de uno de sus interlocutores aymaras, mediante estos pagos se trata de "amurallar" los cerros, crear "círculos de murallas", para hacer tranca de modo 
que la "gente" (el granizo) no pueda pasar; una metáfora visual que nos remite directamente a los muros concéntricos de los sitios aquí abordados. En todo caso, todas las ceremonias religiosas y prácticas rituales oficiadas en estos espacios se inscriben hoy en el dominio de "Gloria", donde se agrupan los principios y fuerzas vitales vinculadas con el mundo celestial y que se contraponen con el universo "saxra" de los diablos y los muertos (Cruz 2015). La adscripción de estos sitios en el campo de Gloria se pone en evidencia en su condición de "cilos", "cielos", "cielitos", "calvarios", o, directamente, "gloria", integrándose muchas veces en el nombre de los cerros donde se encuentran ubicados (p.e. cerros Gloriapata, Cielo Loma, Cielito Lindo, etc.). De la misma manera, salvo contadas excepciones, los SCC se encuentran ubicados en cerros que son considerados por los pobladores locales como "marka qollu" (cerro del pueblo), pudiendo al mismo tiempo considerarse también como "uywiri" (criador). Ambas categorías se encuentran estrechamente vinculadas, presentándose de manera simultánea a nivel familiar y en el de la estancia, en el de la comunidad y en el del ayllu. Marka qollu refiere ciertamente a su condición de cerro-wak'a tutelar, pero no solo en un sentido de protección o providencial, sino también fundacional y formativo de las poblaciones que allí habitan. Así, al asumir sus cargos, las nuevas autoridades de la región de Carangas se colocan un poncho que encarna al cerro-wak'a tutelar de su comunidad de origen, distinguiéndose en esta prenda la parte más sagrada, la cima y la cabeza, y la pampa en la parte inferior (López 1999, p. 22). Al mismo tiempo, como lo señala Rivière (1982, p. 241) en su etnografía sobre Sabaya, las autoridades indígenas de cada comunidad (jilakatas) adoptan al momento de asumir sus cargos el nombre del mallku, que con frecuencia es el cerro-wak'a correspondiente a su estancia. Por su parte, la condición de uywiri refiere más a lo sensible y a lo afectivo, al papel que tienen los cerros-wak'a como criadores, tanto en un nivel personal, familiar o comunal. Tal como lo señalara Martínez (1976, p. 268) tiene que ver con el sentido (uywaña) de criar con amor y de relación muy íntima y profunda de la cual depende el buen resultado de la crianza.

\section{Consideraciones finales}

No pocos investigadores trabajando en distintas partes de los Andes, como los aquí citados Guzmán García (2007), Dalen Luna (2012), Chase (2015), Kosiba (2015), Villanueva Criales (2015), Aguirre Merino (2015), Orsini y Benozzi (2016), e Ibarra Asencios (2016), identificaron cerros cuyas cimas se encontraban marcadas, a modo de un pukara, por una serie de murallas o de plataformas dispuestas de manera concéntrica. De hecho, algunos de los SCC identificados en Carangas fueron registrados en estudios anteriores y analizados desde una perspectiva local. La articulación de la teledetección con las informaciones proporcionadas por las fuentes documentales coloniales, 
la etnografía y los estudios arqueológicos de campo permitieron comprender varios aspectos de esta manifestación religiosa de escala regional. Se trata de sitios ceremoniales con rasgos comunes (localización, muros concéntricos, estilos cerámicos, estructuras votivas, etc.) y que se adscriben inicialmente al periodo de Desarrollos Regionales Tardíos (siglos XII-XV). En este sentido, de la misma manera que los pukara habitacionales, con los que comparten varios atributos, se trata de un fenómeno que se habría expandido durante este periodo sobre todo el Altiplano central, presentándose igualmente en otras regiones de los Andes centrales. Sin embargo, a diferencia de lo que sucede con los pukaras altiplánicos, la mayoría de los SCC continuaron vigentes durante los posteriores periodos Tardío, Colonial y Republicano.

En suma, varios son los aspectos señalados por las fuentes documentales que vinculan estos sitios con cercos concéntricos con los antiguos cultos a los cerros-wak'a tutelares. Pero sobre todas las analogías que se puedan hallar, se encuentra el hecho de que muchos de estos sitios continúan hoy en día funcionando como espacios para ceremonias colectivas. Y si bien en las elocuciones de los pobladores locales el término wak'a no aparece con la misma frecuencia que en los ámbitos académicos, no cabe duda que se trata de la continuidad de una misma estructura religiosa. Wak'a, ancestro, pukara, taypi, pacarina, Gloria, marka qollu, uywiri, etc., todas estas condiciones y formas que interpelan nuestras nociones de materialidad, agencia y personalidad (Bray 2015) pueden confluir, de forma disgregada o formando un todo coherente, en cada uno de los cerros tutelares que existen en las comunidades del altiplano andino.

En 1973 el poeta y escritor boliviano Fernando Díez de Medina se refería a la existencia de "un Cristo andino que tiene por catedrales las montañas". Desde esta mirada, los sitios con cercos concéntricos, y de manera general los cerros tutelares, fueron los templos, las iglesias y las parroquias donde reposaban los wak'a locales, siendo ellos mismos parte de estos wak'a. De allí las grandes preocupaciones que tuvo el cura Bartolomé Álvarez durante su estancia en el altiplano de Carangas y Quillacas. Porque aun si estaba convencido de que su fe podría mover una montaña, él se enfrentaba, cual Quijote y sus molinos de viento, a toda una legión de cerros sacralizados. *

* Manuscrit reçu en avril 2020, accepté pour publication en octobre 2020. 
Cerros, muros concéntricos y divinidades tutelares en el altiplano centro-sur andino

\section{Referencias citadas}

ABercrombie Thomas

1998 Pathways of Memory and Power. Ethnography and History Among an Andean People, University of Wisconsin Press, Madison.

Acosta Joseph de

1894 [1590] Historia natural y moral de las Indias, Ramón Anglés Impresor, Madrid. Aguirre Merino Christiam

2015 Puñay. El secreto de una pirámide, Escuela Superior Politécnica del Chimborazo, Riobamba.

Álvarez Bartolomé

1998 [1588] De las costumbres y conversión de los indios del Perú, Polifemo, Madrid. ARKUSH Elizabeth

2012 "Los pukaras y el poder: los collas en la cuenca septentrional del Titicaca", in Luis Flores Blanco y Henry Tantaleán (eds), Arqueología de la cuenca del Titicaca, Instituto Francés de Estudios Andinos, Lima, p. 295-319.

Arriaga Pablo de

1621 La extirpación de la Idolatría en el Perú, Geronymo de Contreras Impresor, Lima. Ávila Francisco de

1966 [1611] "Relación que yo el Dr. Francisco de Avila, presbítero, cuyra y beneficiado de la ciudad de Guánuco", in José-María Argüedas y Pierre Duviols (eds), Dioses y hombres de Huarochirí, Museo Nacional de Historia/IEP, Lima, p. 255-259.

BERTONIO Ludovico

1984 [1612] Vocabulario de la lengua aymara, Ceres, La Paz.

Bouysse-CASSAgne Thérèse

1978 “L’espace aymara: urco et uma”, Annales. Economies, sociétés, civilisations, 56, p. 1057-1080.

1987 La identidad aymara: aproximación histórica (siglo XV, siglo XVI), Instituto de Historia Social de Bolivia/Instituto Francés de Estudios Andinos, La Paz.

2010 "Apuntes para la historia de los puquina-hablantes", Boletín PUCP, 14, p. 283-308.

Bouysse-CAssagne Thérèse y Juan Chacama

2012 "Partición colonial del territorio, cultos funerarios y memoria ancestral en Carangas y precordillera de Arica (siglos XVI-XVII)", Chungará, 44 (4), p. 669-689.

BRAY Tamara

2003 "Inka pottery as culinary equipment: food, feasting, and gender in Imperial State design", Latin American Antiquity, 14, p. 3-28.

2015 "Andean Wak'as and alternative configurations of persons, power, and things", in Tamara Bray (ed.), The Archaeology of Wak'as. Explorations of the Sacred in the Pre-Columbian Andes, University Press of Colorado, Boulder, p. 167-212.

CHASE Zachary

2015 "What is a wak'a? When is a wak'a? “, in Tamara Bray (ed.), The Archaeology of Wak'as. Explorations of the Sacred in the Pre-Columbian Andes, University Press of Colorado, Boulder, p. 75-126. 
Cruz Pablo

2015 "Pensando en Supay o desde el Diablo", in Lucila Bugallo y Mario Villca (eds), Wak'as, diablos y muertos. Alteridades significantes en el mundo andino, Inst. Int. Tilcara/UBA/IFEA, Jujuy, p. 171-201.

Dalen Luna Pieter D. van

2012 "Investigaciones arqueológicas en el Castillo de Pasamayo: un sitio amurallado Chancay en el valle bajo del río Chancay-Huaral", Arqueología y Sociedad, 24, p. 301-332.

Díez De Medina Fernando

1973 La teogonía andina, Municipalidad de La Paz, La Paz.

Duviols Pierre

1967 "Un inédit de Cristobal de Albornoz: La instrucción para descubrir todas las guacas del Pirú y sus camayos y haziendas", Journal de la Société des américanistes, 56 (1), p. 7-39.

1979 'Un Symbolisme de l'occupation, de l'aménagement et de l'exploitation de l'espace. Le monolithe huanca et sa fonction dans les Andes préhispaniques", L'Homme, 19 (2), p. 7-31.

EsTEnsSORo Fuchs Juan Carlos

2003 Del paganismo a la santidad. La incorporación de los indios del Perú al catolicismo, 1532-1750, IFEA, Lima.

FERNÁndeZ JuÁrez Fernando

2002 Aymaras de Bolivia: entre la tradición y el cambio cultural, Abya Yala, Quito. GISBERT Teresa

1994 "El señorío de los Carangas y los chullpares del Río Lauca", Revista Andina, 12 (2), p. 427-485.

GonZÁleZ DE Holguín Diego

1952 [1608] Vocabulario de la lengua general de todo el Perú llamada lengua quichua, Instituto de Historia, Lima.

Guaman Poma de Ayala Felipe

1989 [1615] Nueva coronica y buen gobierno, edición facsímil, Institut d'ethnologie, Paris.

GuZmán García Carlos

2007 “Las 'fortalezas’ prehispánicas de Lima”, Arkinka, 140, p. 76-87.

HeRnández Príncipe Rodrigo

1923 [1621] "Mitología andina. Idolatrías en Recuay", Revista Inca, 1, p. 25-78.

IBARRA AsEnCIOS Bebel

2016 "Estrategias de ocupación inca en la Sierra de Ancash: el rol de tambos y colcas en la definición de provincias incas", in Bebel Ibarra A. (ed.), Arqueología de la Sierra de Ancash 2: Población y territorio, Instituto de Estudios Huarinos, Huari, p. 179-210.

Korpisaari Antti, Jedú Sagárnaga, Juan Villanueva y Tania Patiõo

2012 "Los depósitos de ofrendas tiwanakotas de la isla Pariti, lago Titicaca, Bolivia", Chungara, 44, p. 247-267. 
Cerros, muros concéntricos y divinidades tutelares en el altiplano centro-sur andino

Kosiba Steve

2015 "Of blood and soil: tombs, Wak'as, and the naturalization of social difference in the Inka Heartland", in Tamara Bray (ed.), The Archaeology of Wak'as. Explorations of the Sacred in the Pre-Columbian Andes, University Press of Colorado, Boulder, p. 167-212.

Kosiba Steve y Vicentina Galiano Blanco

2013 "Construyendo un paisaje inka: la conversión de centros ceremoniales y la constitución de la autoridad durante la formación del estado inkaiko (Cusco, Perú)", Arqueología y Sociedad, 26, p. 301-338.

Lima Pilar

2012 "Caranguilla: la capital prehispánica de los carangas? Reestructuración de la perspectiva territorial a partir de la presencia de los inkas", in Ximena Medinacelli (coord.), Turco Marka. Hombres, dioses y paisaje en la historia de un pueblo orureño, IEB/Fundación Cultural BCB, La Paz, p. 49-74.

LÓPEZ Ulpián

1999 "Niños, cargos y yatiris en Carangas. Una aproximación al caminar andino", Eco andino, 4 (7-8), p. 8-33.

Martínez Gabriel

1976 El sistema de los uywiris en Isluga, Centro Isluga de Investigaciones Andinas, Iquique.

1983 "Los dioses de los cerros en los Andes", Journal de la Société des américanistes, 69, p. 85-115.

Martínez Rosalía

2010 "La música y el Tata Pujllay: carnaval entre los Tarabuco (Bolivia)", in Arnaud Gerard (ed.), Diablos tentadores y pinkillos embriagadores, Plural, La Paz, p. 143-181.

Martínez Cereceda José Luis

2004 "Discursos de alteridad y conjuntos significantes andinos", Chungará, 36 (2), p. 505-514.

Michel Marcos

1999 El Señorío Prehispánico de Carangas, Diplomado Superior en Derechos de los Pueblos Indígenas, Universidad de la Cordillera, La Paz.

2008 Patrones de asentamiento precolombino del altiplano Boliviano. Lugares centrales de la región de Quillacas, Departamento de Oruro, Bolivia, Tesis doctoral, Department of Archaeology and Ancient History, African and Comparative Archaeology, Uppsala University, Uppsala/Instituto de Investigaciones Antropológicas y Arqueológicas, Universidad Mayor de San Andrés, La Paz.

Murúa Martín de

2004 [1590] Códice Murúa. Historia y genealogía de los reyes Incas del Perú del padre mercenario Fray Martín de Murúa: Códice Galvin, Testimonio Compañía Editorial, Madrid.

Nielsen Axel y William Walker

1999 "Conquista ritual y dominación política en el Tawantinsuyu: el caso de Los Amarillos (Jujuy, Argentina)", in Andrés Zarankin y Félix Acuto (eds), Sed Non Satiata. Teoría social en la arqueología latinoamericana contemporánea, Ediciones del Tridente, Buenos Aires, p. 153-169. 
Orsini Carolina y Elisa BenOzZI

2016 "Arqueología de una pacarina andina”, in Bebel Ibarra A. (ed.), Arqueología de la Sierra de Ancash 2: Población y territorio, Instituto de Estudios Huarinos, Huari, p. 107-136.

PÉNTEK Attila y Norbert FARAGó

2019 "Basalt utilization in the archaic period of Bolivia. Geological and archaeological background", Archaeometry Workshop, 2019 (2), p. 109-126.

Platt Tristán, Thérèse Bouysse-CAssagne y Olivia Harris

2006 Qaraqara-Charka. Mallku, Inka y Rey en la Provincia de Charcas. Historia antropológica de una confederación aymara, IFEA/Plural-Fundación Cultural BCB, La Paz.

RAFFINO Rodolfo

2004 El Shincal de Quimivil, Editorial Sarquís, Catamarca.

RAMOS GAVILÁn Alonso

1976 [1621] Historia de Nuestra Señora de Copacabana, Academia Boliviana de Historia, La Paz.

RIVIÈRE Gilles

1982 Sabaya. Structures-économiques et représentations symboliques dans le Carangas-Bolivie, Tesis doctoral, Etnología, EHESS, Paris.

Santo Tomás Domingo de

1951 [1560] Lexicón o vocabulario de la lengua general del Perú, Universidad Nacional Mayor de San Marcos, Lima.

TARRAGó Myriam

2011 "Poblados tipo pukara en Yocavil. El plano de Rincón Chico 1 (Catamarca, Argentina)", Estudios Sociales del NOA, 11, p. 33-61.

VAZQuez de Espinosa Antonio

1948 [1629] Compendio y descripción de las Indias Occidentales, Smithsonian Institution, Washington.

Villanueva CRiales Juan

2015 "Evaluando la frontera Pacajes-Carangas para el período Intermedio Tardío (1100-1450 d.C.) en el Altiplano boliviano central a partir de análisis de pastas cerámicas", Chungará, 47 (2), p. 211-218. 